\title{
Docencia de contabilidad internacional en el sistema universitario español. Metodologías docentes y sistemas de evaluación
}

\author{
Teaching of International Accounting in the Spanish University System. \\ Teaching methodologies and assessment systems
}

\author{
Luis Rodríguez Domínguez (Irodomin@usal.es) \\ Instituto Multidisciplinar de Empresa - Universidad de Salamanca (España) \\ http://dx.doi.org/10.12795/EDUCADE.2018.i09.02
}

\begin{abstract}
RESUMEN: La reforma de las titulaciones y la adaptación al Espacio Europeo de Educación Superior han supuesto un cambio potencial de las metodologías docentes y de los sistemas de evaluación, con un enfoque centrado en la adquisición de competencias, más cercanas a lo que demanda la realidad social y empresarial. Entre las competencias que deben desarrollarse más en la educación en contabilidad, destacan la capacidad de trabajar en equipo, la resolución de problemas y las capacidades de comunicación oral y escrita. Para la consecución de dichas competencias, se aboga por el uso de metodologías más activas, como el trabajo en equipo o el uso de entornos virtuales de aprendizaje, así como por sistemas de evaluación continua.
\end{abstract}

En este contexto, el presente trabajo analiza la docencia de Contabilidad Internacional en el sistema universitario español. Esta materia ha adquirido una importancia creciente en el entorno empresarial y normativo actual, con una docencia diseñada en el contexto del EEES.

Con este fin, se han revisado las Fichas docentes de esta asignatura entre las 75 universidades españolas. Se ha detectado una importante omisión de esta materia en los Planes de Estudio españoles, así como una falta de información completa en muchas Fichas. El método expositivo sigue teniendo un marcado protagonismo en la metodología, al igual que el examen final. Sin embargo, se detecta un mayor rango y diversidad de metodologías y sistemas de evaluación. Se observa también una escasa presencia del estudio de casos, que suele ser la metodología más sugerida a nivel internacional para la docencia de esta materia. Asimismo, cabe destacar la necesidad de un mayor peso tanto del trabajo en equipo como de la evaluación continua.

PALABRAS CLAVE: Contabilidad Internacional; Metodologías docentes; Educación en contabilidad; Sistemas de evaluación; Trabajo en equipo; Evaluación continua.

\begin{abstract}
The reform of Degrees and the implementation of the European Higher Education Area (EHEA) have involved a potential change in teaching methodologies and assessment systems, with an approach based on developing skills, closer to social and managerial demands. Among the skills that must be developed by accounting education, teamwork skills, problemsolving and communication skills specially stand out. To pursue these competences, the use of active methodologies (such as work in groups or learning virtual environments) is encouraged, at the same time that continuous evaluation systems are proposed.

In this context, the current study aims to analyze how International Accounting is taught in the Spanish university system. This subject has raised its importance in the current corporate and regulatory context. Its teaching has been designed within EHEA environment, with an approach focused on skills.

With that aim, we have revised the Academic Records of this subject in the 75 Spanish universities. We have detected a significant omission of this subject in the Spanish curricula and a lack of complete information in many records. Teaching mainly relies on lectures and final exams. However, a broader and more diverse range of methodologies and evaluation systems is detected. Also, case studies are scarcely used, in spite of being suggested as a preferred methodology in the international context. The results obtained point out the need for promoting work in groups and continuous evaluation.
\end{abstract}


KEYWORDS: International accounting; Teaching methodologies; Accounting education; Evaluation systems; Work in groups; Continuous evaluation.

Artículo. Recibido: 30-10-17 - Versión revisada: 23-02-18, Aceptado: 30-04-18

Licencia Creative Commons BY NC ND · $2018 \cdot$ Asociación Española de Contabilidad y Administración de Empresas - AECA

\section{INTRODUCCIÓN}

La implantación de los nuevos Grados y la adaptación al Espacio Europeo de Educación Superior (EEES) han planteado un desafío y han posibilitado un cambio de enfoque en el proceso de enseñanza-aprendizaje. El nuevo contexto ha conllevado una implicación activa del estudiante en la adquisición de conocimiento, promoviendo metodologías que faciliten el aprendizaje autónomo y el desarrollo de competencias vinculadas al ejercicio profesional (Florez y Abelda, 2012).

Estas circunstancias de adaptación han generado también una gran oportunidad en las titulaciones relativas a administración de empresas, en las que se detectaban carencias significativas y un distanciamiento entre la educación universitaria y la formación requerida a los estudiantes por las empresas (Marín-García et al., 2008). En este sentido, los Grados permiten un mayor acercamiento del título universitario a la demanda social y empresarial (Calderón et al., 2013), fomentando la empleabilidad y desarrollando un enfoque más aplicado de los estudios universitarios. Las empresas demandan profesionales con capacidad crítica y con las competencias y habilidades suficientes para poder adaptarse a un entorno económico cambiante (Pascual et al., 2011 , p. 68).

Precisamente, el término 'competencias' es esencial en el nuevo proceso, definiéndose como 'los conocimientos, destrezas y actitudes necesarios para ejercer una profesión, poder resolver problemas profesionales de forma autónoma y flexible, y estar capacitado para colaborar con su entorno profesional y en la organización del trabajo' (Bunk, 1994, p. 9). Tal como argumentan Gómez-Ruiz y Naranjo-Gil (2011, p. 194), la gestión de competencias cobra un papel fundamental en la docencia universitaria, puesto que los perfiles profesionales cerrados en base a funciones han quedado obsoletos, y en la actualidad, los puestos de trabajo se definen en base a competencias, con un carácter más abierto y con mayor capacidad de flexibilidad y adaptación.

El enfoque hacia las competencias enmarca un nuevo estilo de trabajo del docente y un cambio de paradigma respecto al proceso de enseñanza-aprendizaje (Martí y Orgaz, 2014). Todo ello lleva a una reformulación de las metodologías docentes, que favorezcan la participación activa del estudiante en la consecución de tales competencias; entre las metodologías propuestas destaca especialmente el trabajo en equipo, conjuntamente con métodos tradicionales dentro de la docencia española, como la lección magistral o la resolución de casos prácticos. De forma simultánea, han de modificarse los sistemas de evaluación, que dejarán de basarse principalmente en el examen final de carácter global y se centrarán en un conjunto de actividades de evaluación continua, que permita un mayor seguimiento del proceso de aprendizaje por parte del alumno y una evaluación más completa de las competencias alcanzadas. En otras palabras, el sistema de evaluación debe estar alineado con los nuevos objetivos.

En el ámbito concreto de la docencia en contabilidad, considerada entre las materias más relevantes para el ejercicio de la profesión de economista / administrador de empresas (Arquero et al., 2009; ANECA, 2005), diversos estudios (Arquero, 2000; Arquero y Tejero, 2011) consideran que se deberían incluir como objetivos educativos el 
desarrollo de ciertas habilidades y competencias no técnicas, no estrictamente contables, pero que forman parte imprescindible del perfil del contable profesional, como las capacidades de comunicación, de trabajo en equipo y de resolución de problemas. Colectivos de docentes y profesionales (Periáñez et al., 2010), así como diferentes instituciones (IFAC, 2008), insisten en que el desarrollo de estas capacidades debe ser objetivo de la formación superior.

Sin embargo, la docencia tradicional de la contabilidad, especialmente en los primeros cursos, está enfocada hacia las clases magistrales, con una evaluación tendente a basarse primordialmente en exámenes finales. Este enfoque no resulta adecuado en el nuevo contexto de los Grados adaptados al EEES, en el que la adquisición de conocimientos técnicos queda configurada como simplemente una de las distintas competencias a alcanzar. La consecución de estas competencias obliga a reformular y ampliar las estrategias de docencia y de evaluación, teniendo en consideración además el perfil habitual de los estudiantes de contabilidad. En este sentido, para que el proceso de desarrollo de competencias sea un éxito, los estudiantes deben ser independientes, participativos y colaborativos; pero ciertamente los estudiantes de contabilidad son menos independientes y más competitivos que los estudiantes matriculados en otras ciencias sociales (Arquero y Tejero, 2011), dificultando por tanto la adaptación al EEES.

Entre las asignaturas impartidas en el ámbito de la contabilidad, el peso de la Contabilidad Internacional es creciente. DeWet y Van Niekerk (2001) incluyen el énfasis en la Contabilidad Internacional como una de las tendencias recientes y más prevalentes en la educación en contabilidad, como consecuencia de la globalización de las economías, la internacionalización de los mercados de capitales y la creciente aceptación de las normas contables internacionales. Al respecto, es necesario contar con profesionales con una formación más sólida, dado que la norma contable es más compleja, mutable y extensa que en el pasado, y además su aplicación precisa juicios técnicos más sofisticados y frecuentes (Escobar y Jiménez, 2009). Su docencia a través exclusivamente de clases magistrales y de examen final puede ser excesivamente restrictiva, pues no permitiría alcanzar competencias consideradas parte fundamental del perfil profesional de un contable por parte de profesionales y de organismos (IFAC, 2008), como la capacidad de trabajar en equipo, la provisión de herramientas para facilitar un aprendizaje a lo largo de la vida, capacidad de comunicación, razonamiento crítico, etc.

En consecuencia, la docencia de Contabilidad Internacional debe abarcar un conjunto más amplio de metodologías docentes, más allá de las seguidas tradicionalmente en la universidad española (lección magistral o método expositivo y resolución de ejercicios), al mismo tiempo que las competencias a alcanzar con su docencia deben evaluarse con un rango más diverso de actividades, generando una evaluación continua. Frente a otras asignaturas de materia contable (por ejemplo, Contabilidad Financiera, Contabilidad de Costes o Análisis Contable), la docencia en forma de una asignatura individualizada es relativamente reciente. Aunque generalmente solía formar parte de los programas de Contabilidad Financiera, haciendo especial referencia a los procesos de armonización contable internacional, en varias universidades han sido las reformas de las titulaciones en los años 90 o, más recientemente, la adaptación de las anteriores Licenciaturas a los nuevos Grados hechos determinantes de su consideración como asignatura específica en los Planes de Estudio. A ello se ha unido, obviamente, el peso creciente de la Contabilidad Internacional, por cuanto numerosos aspectos de la consolidación de cuentas anuales - de la auditoría no podrían comprenderse completamente sin la alusión a la normativa internacional, especialmente aquella emanada del International Accounting Standards Board (IASB), la normativa IFRS (International Financial Reporting 
Standards). Por tanto, estamos hablando de una asignatura reciente en muchos casos, que surge con un enfoque hacia competencias.

En este contexto, resulta de interés y utilidad analizar hasta qué punto el proceso de enseñanza-aprendizaje de Contabilidad Internacional ha absorbido estos planteamientos, adoptando una variedad de metodologías docentes y de actividades de evaluación de cara a alcanzar las competencias propuestas. El objetivo de este estudio es realizar una visión panorámica de la docencia de Contabilidad Internacional entre las universidades españolas como asignatura autónoma, analizando su oferta, la disponibilidad de información sobre los aspectos clave del proceso de enseñanza-aprendizaje, las metodologías docentes propuestas y los sistemas de evaluación planteados. A partir de los resultados obtenidos, se extraerán unas conclusiones y una serie de implicaciones sobre la docencia en materia contable. Para ello, se han revisado las Fichas docentes de las asignaturas de Contabilidad Internacional impartidas en las 75 universidades que conforman el sistema universitario español y que han sido expuestas en sus páginas web de Grados y Master. La publicación de información sobre el contenido de las asignaturas forma parte del estándar de evaluación en el seguimiento de las titulaciones por parte de los organismos evaluadores. A partir de estas Fichas, se obtiene la información facilitada al alumno, que constituirá la guía de su proceso de aprendizaje sobre Contabilidad Internacional, siendo, por tanto, la carta de presentación de la asignatura al exterior.

El presente estudio se estructura en los siguientes apartados: Tras esta Introducción, la sección 2 expone diversas líneas de la literatura previa que se han centrado en la docencia de contabilidad internacional. El apartado 3 recoge los principales objetivos y competencias que se pretenden alcanzar con la docencia de Contabilidad Internacional. A continuación, las secciones 4 y 5 exponen diversas metodologías docentes y sistemas de evaluación que pueden resultar especialmente efectivos para la consecución de las competencias, con un especial énfasis en el trabajo en grupo y en la evaluación continua; la sección 6 describe los resultados del análisis, realizando una visión panorámica de la docencia de Contabilidad Internacional en el sistema universitario español, las metodologías docentes y los sistemas de evaluación; en la sección 7 se discuten los resultados, y finalmente la sección 8 recoge las conclusiones del estudio.

\section{DOCENCIA DE CONTABILIDAD INTERNACIONAL: ESTUDIOS PREVIOS}

Aunque la internacionalización de los programas en contabilidad ha sido un tema recurrente de las organizaciones profesiones desde principios de los 70 (AICPA, 1992; Ahscroft et al., 2008), en los últimos 25 años ha recibido especial atención por parte de los académicos y de las instituciones universitarias. Sin duda alguna, ante la creciente globalización de los negocios, la amplia aceptación de las normas IFRS en el mundo empresarial y su influencia en las regulaciones contables nacionales, la dimensión internacional se ha convertido en un aspecto de gran relevancia para la profesión contable (Adhikari et al., 1999), con la necesidad de integrar la normativa IFRS dentro del currículo contable (Thomas, 2009).

Precisamente la forma de inclusión de esta materia en los programas educativos en contabilidad ha generado, al menos, cuatro cuestiones de amplio debate en la literatura previa: si se oferta como una asignatura separada o como una materia integrada en otras asignaturas más generales (esto es, si deberían integrarse los conceptos internacionales en las asignaturas ya existentes o debería establecerse una asignatura separada); si corresponde a la docencia en grado o más bien de postgrado; cuál sería la temática concreta de contabilidad internacional que se abordaría; cómo se ha llevado a cabo el proceso de adopción de IFRS en los 
diferentes países y cuál ha sido la repercusión de este proceso sobre la docencia, con las dificultades y desafíos que implica.

Diversos estudios han planteado cuestionarios para analizar si deberían integrarse los conceptos internacionales en las materias ya existentes o si debería establecerse un curso separado. Se ha estudiado el grado de cobertura de la contabilidad internacional en diferentes países y regiones, como Estados Unidos (Adhikari et al., 1999; Munter y Reckers, 2009), Europa (Stolowy y Tenenhaus, 1998) o Reino Unido (Adams y Roberts, 1994), analizando, entre otros aspectos, la oferta como asignatura separada o integrada en otras materias. Mientras que en Estados Unidos un 36,2\% de las universidades ofertaban esta materia como asignatura separada en grado y un $59,2 \%$ en postgrado (Adhikari et al., 1999), el estudio de Stolowy y Tenenhaus (1998) en Europa mostraban cifras del $41,7 \%$ en forma de curso separado, 36,3\% en forma de asignaturas con temas integrados de contabilidad internacional y un $22 \%$ de las universidades que no ofertaban dicha materia. En el caso de España, el citado estudio indicaba una cifra del 53,7\% como asignatura separada, $15,4 \%$ como materia integrada en otras asignaturas y un $30,8 \%$ de las instituciones que no incluían esta temática entre sus planes de estudio. En el caso del Reino Unido, entre un $33 \%$ y un $50 \%$ de las universidades ofrecían cursos de grado o de postgrado que cubrían temáticas de contabilidad internacional, con un enfoque centrado principalmente en ofertar esta materia como asignatura específica.

Numerosos autores (v.g. Rezaee et al., 1997; Stout y Schweikart, 1989; Huang y Mintz, 1992; Stolowy y Tenenhaus, 1998) abogan por su oferta como curso separado. En este sentido, Adams y Roberts (1994) consideran que muchas facetas de la contabilidad internacional no pueden ser adecuadamente consideradas únicamente con un enfoque de integración. Rezaee et al. (1997) argumentan que un curso separado proporcionaría una mejor cobertura de temas internacionales, dando más protagonismo a los temas más estrictamente contables. Stolowy y Tenenhaus (1998) concluyen que la consideración como curso específico se va convirtiendo en una tendencia creciente a nivel europeo, tendencia que coincide con las preferencias de los profesionales (Rezaee et al., 1997).

Una vez analizada el grado de cobertura por las instituciones educativas, diversos trabajos se centran en la ubicación de la contabilidad internacional como materia a impartir dentro del curriculum de un grado o como parte de un programa de postgrado. Buena parte de la literatura se ha centrado en la docencia dentro de Estados Unidos y en Reino Unido (ej. Adhikari et al., 1999; Adams y Roberts, 1994), mostrando que en Estados Unidos existe una preferencia por incluir la materia dentro de los programas de postgrado, mientras que en el Reino Unido se adoptan como asignatura de grado ('undergraduate'). La razón de esta discrepancia subyace en el diferente énfasis de los estudios de contabilidad: en Estados Unidos, la educación contable a nivel de Grado tiende a enfatizar más las cuestiones técnicas y en la competencia técnica (Adhikari et al., 1999), más que las cuestiones y conceptos teóricos que conforman la educación de grado en muchos otros países. En España, Arquero et al. (2009) muestran la preferencia de los egresados a considerar que esta materia debería impartirse en postgrado; el grado debería centrarse en explicar el Plan General de Contabilidad español, aunque mencionando la normativa internacional para que los estudiantes se vayan familiarizando con el nuevo entorno.

Otro de los aspectos controvertidos en la literatura sobre la docencia en contabilidad internacional es el alcance de los contenidos a impartir, esto es, las temáticas del programa. En primer lugar, cabe subrayar las notables diferencias entre las universidades norteamericanas y las universidades de fuera de Estados Unidos en lo que respecta a la importancia percibida de algunos temas internacionales (Conover et al., 1994; Adhikari et al., 1999; Adams y Roberts, 1994; Stolowy y Tenenhuaus, 1998). 
Mientras que en las universidades europeas los programas desarrollan temas de contabilidad comparativa y la cuestión de la armonización, las universidades norteamericanas tienden a centrar sus cursos en los problemas contables a los que se enfrentan las empresas multinacionales, como transacciones en moneda extranjera, contabilidad de gestión, evaluación del rendimiento multinacional, etc (Conover et al., 1994; Adhikari et al., 1999; Stolowy y Tenenhaus, 1998).

La revisión de la literatura previa evidencia dificultades a la hora de clarificar cuáles deben ser los objetivos a cumplir en contabilidad internacional (Adams y Roberts, 1994), lo cual lleva a una falta de uniformidad en la cobertura de temas específicos internacionales, falta de acuerdo en relación a lo que constituye la cobertura básica y la consiguiente falta de consenso en relación a la importancia relativa de temas concretos internacionales (Rezaee et al., 1997). No obstante, en este contexto, es especialmente destacable el peso creciente de la normativa IFRS entre las temáticas ofertadas, frente a los estudios anteriores (Ashcroft et al., 2008). Y ello ha surgido principalmente como consecuencia de la adopción de IFRS en numerosos países, con las relevantes repercusiones que ello ha tenido sobre la docencia en contabilidad.

En efecto, buena parte de la literatura previa sobre contabilidad internacional se centra en los procesos de adopción de las normas IFRS en diferentes países, como Francia (Bonnier et al., 2013), Sudáfrica (Coetze y Schmulian, 2013), Brasil (Nelson y Salotti, 2012), Australia (Jackling et al., 2013), Reino Unido (Stoner y Sangster, 2013), o Rusia (Vysotskaya y Prokofieva, 2013). Esta adopción implicaba consecuencias que dependían, entre otros, de dos factores: el alcance de implantación, esto es, si afectaba únicamente a cuentas consolidadas (como en la mayoría de países europeos) o a todas las cuentas (como en Brasil); y el salto cualitativo que se producía con respecto al sistema contable de partida (por ejemplo, en el Reino Unido, las normas contables seguían un esquema basado en principios, más que en reglas, parecido al seguido por el IASB; en cambio, la mayoría de los países europeos continentales seguían un esquema basado en reglas, muy alejado en sus fundamentos del esquema IFRS).

La implantación de la normativa IFRS tuvo unas consecuencias muy relevantes en la docencia en contabilidad internacional, con impacto en otras disciplinas contables. Como se ha señalado, esta normativa se basa en principios, más que en reglas, por lo que supone cambios importantes en la pedagogía. Tal como exponen Bonnier et al. (2013) para el caso francés, se produce una evolución desde un enfoque orientado al registro de las transacciones ('llevanza de libros') a un enfoque en el que los estudiantes han de definir y analizar las diferentes transacciones con respecto a un Marco Conceptual utilizando conceptos económicos y financieros más amplios, con una mayor elaboración de juicios contables y análisis de las repercusiones que la contabilización implica. Mientras que la docencia tradicional generalmente pretendía que el estudiante fuera excelente en el registro y que presentase el Balance y la Cuenta de Resultados conforme a la normativa, tratar con IFRS requiere una interpretación económica de las transacciones y un conocimiento especializado, no sólo en métodos cuantitativos, matemáticas financieras, finanzas corporativas, etc. (Nelson y Salotti, 2013). Este cambio de enfoque suponía un auténtico desafío para aquellos países que partían de una filosofía 'code-law' y una contabilidad dirigida a los impuestos (Jackling, 2013).

Este desafío y este cambio de pedagogía han generado bastantes dificultades docentes, tanto desde el punto de vista de los estudiantes como de la perspectiva del profesorado. Por una parte, muchos estudiantes prefieren un modelo de aprendizaje basado en reglas, más centrado en nociones de 'correcto vs. incorrecto' (Jackling, 2013). Sin embargo, con la normativa internacional, para los estudiantes ni es instructivo ni útil enseñar soluciones estandarizadas a los problemas contables (Bonnier 
et al., 2013), sino que han de aplicar juicios y estimaciones. Este nuevo contexto conlleva cambios en la metodología, con la necesidad de proporcionar a los alumnos herramientas para realizar juicios basados en los requerimientos de las IFRS (Wells, 2011; Jackling et al., 2013), con un amplio uso de estudios de casos (Munter y Reckers, 2009; Nelson y Salotti, 2013; Bonnier et al., 2013; Needles, 2010). Por otra parte, se ha evidenciado reticencia por parte de los profesores a revisar su metodología docente (Jackling et al., 2013), teniendo en cuenta además la ausencia de manuales de apoyo y de recursos didácticos (Coetze y Schmulian, 2013) para preparar apropiadamente la docencia de contabilidad internacional. No cabe duda de que esta materia resulta más difícil de preparar y de evaluar (Bonnier et al., 2013) y que el desarrollo de materiales IFRS es especialmente trabajoso (Jackling et al., 2013), ya se requiere cambiar el foco desde simplemente transferir conocimientos técnicos al desarrollo de habilidades y principios más apropiados para ejercer los juicios basados en IFRS.

En consecuencia, aunque la implantación de IFRS ha proporcionado una oportunidad a los profesores para repensar y examinar críticamente su enfoque de docencia, la adaptación docente ha tenido bastantes reticencias y obstáculos (Adhikari et al., 1999). Por un lado, muchas universidades ya tienen un curriculum contable saturado, que no permite la incorporación de un curso adicional sobre contabilidad internacional. De hecho, se detecta una preferencia por ampliar el curriculum con otro tipo de contenidos (Munter y Reckers, 2009), como ética, contabilidad forense, controles internos, etc. En el caso español, Arquero et al. (2009) muestran el escaso apoyo que tienen las normas internacionales de información financiera como materia a incluir en el curriculum, debido a que se consideran escasamente importantes (probablemente porque el alumno tipo acabe trabajando en pymes en las que apenas tiene aplicación la normativa internacional) y susceptibles de ser tratadas en asignaturas optativas o de postgrado. Por otro lado, se ha subrayado la falta de experiencia del profesorado en esta materia, que se agudiza con las dificultades de preparación de la misma y con el menor grado de aprovechamiento para otros fines (como la investigación). La falta de recursos docentes se ha destacado en artículos previos (Jackling, 2013; Coetze y Schmulian, 2013), indicando la necesidad de estudios de casos (Nelson y Salotti, 2013), aunque los principales organismos implicados en la armonización contable y las compañías de auditoría cada vez tienen unos mayores recursos didácticos disponibles (Larson y Street, 2011). En conclusión, ante estas dificultades, Zhu et al. (2011) describen varios factores que suelen influir positivamente en la decisión de cubrir la contabilidad internacional en los diferentes cursos y programas ofertados por las universidades: la percepción de una adopción cercana de las normas IFRS en el país donde se radica la universidad, el tamaño de la institución, la disponibilidad de margen de tiempo para incluir, aunque sea brevemente, la temática, la presencia de profesores interesados en enseñar cuestiones de contabilidad internacional y la experiencia profesional del profesorado; por otra parte, se subrayan diversas barreras prácticas que influyen en la decisión, entre las que destaca la baja disponibilidad de materiales docentes sobre IFRS.

\section{OBJETIVOS Y COMPETENCIAS EN CONTABILIDAD INTERNACIONAL}

La asignatura de Contabilidad Internacional suele contemplarse como un complemento a la formación contable del estudiante en temas empresariales y corporativos. Como se ha indicado anteriormente, esta asignatura ha cobrado una mayor importancia en los últimos años, como consecuencia de la adopción del marco contable del International Accounting Standards Boards (IASB) para la elaboración de estados financieros consolidados a nivel de la Unión Europea y del proceso de armonización contable vigente en la esfera internacional. Por ello, una vez que el estudiante conoce los temas nacionales de Contabilidad Financiera, se adentra en la Contabilidad de Costes y Contabilidad de Gestión y aprende claves de interpretación 
de informes anuales a través del Análisis Contable, esta asignatura cuadraría su formación en contabilidad, conjuntamente con los conocimientos sobre Consolidación de Cuentas y Auditoría.

Por ello, el resultado de aprendizaje propuesto es que el estudiante aprenda a pensar en los términos establecidos en las Normas Internacionales de Contabilidad. Este objetivo tan genérico suele desagregarse en las Fichas Docentes de esta asignatura en una serie de objetivos más concretos:

- Analizar las respuestas que han proporcionado los organismos internacionales de armonización contable para reducir la diversidad contable, con especialmente énfasis en el modelo del IASB

- Conocer los principales organismos internacionales encargados de la emisión de normas relacionadas con la información financiera a nivel mundial

- Identificar los diferentes regímenes contables internacionales, a partir de sus características diferenciadoras

- Familiarizarse con la estructura y contenidos de las normas emitidas por el IASB

- Conocer el contenido de los distintos apartados que integran el Marco conceptual de la Información Financiera emitido por el IASB

- Resolver los problemas de valoración y de registro de las distintas transacciones con activos empresariales, de las operaciones con pasivos, así como las partidas del patrimonio neto, en el contexto de las NIC/NIIF

- Valorar y registrar los ingresos y gastos de conformidad con las reglas contenidas en diversas NIC/NIIF

- Identificar las principales similitudes y discrepancias de la normativa contable española con las Normas Internacionales de Información Financiera

Complementando estos objetivos de aprendizaje, las Fichas Docentes de las asignaturas de Contabilidad Internacional han establecido un conjunto de competencias a alcanzar por parte del estudiante durante y después de la docencia de esta asignatura. Este conjunto de competencias suele incluir tres perspectivas: genéricas, específicas y transversales, expuestas en la Tabla 1.

\section{METODOLOGÍAS DOCENTES POTENCIALES}

Según lo señalado anteriormente, la adaptación al Espacio Europeo de Educación Superior ha centrado la docencia en la consecución de una serie de competencias. En esta línea, las universidades se hacen eco de las opiniones de las empresas, que demandan profesionales con capacidad crítica y con las competencias y habilidades suficientes para poder afrontar un entorno económico cambiante (Pascual et al., 2011). En consecuencia, se incentivan estrategias de enseñanza-aprendizaje no sólo basadas en los contenidos, como era tradicional en la universidad española, sino también basadas en las competencias (Durán et al., 2013).

En este sentido, Gandía y Montagud (2011, p. 679) subrayan la necesidad de que, en la disciplina contable, se introduzcan cambios metodológicos que afecten no sólo a los contenidos a impartir, sino también a los sistemas de evaluación y al uso de innovaciones que permitan a los estudiantes desarrollar competencias y habilidades profesionales propias del área de conocimiento. Para ello, se aboga por la transición desde un modelo centrado en la enseñanza a un modelo centrado en el aprendizaje del estudiante, que promueva la actividad autónoma del mismo y que lo oriente hacia la obtención de competencias.

Pueden usarse más epígrafes, pero en línea general, siguiendo esta estructura argumental. 
Tabla 1. Competencias de la asignatura de Contabilidad Internacional

\begin{tabular}{|c|c|c|}
\hline Genéricas & Específicas & Transversales \\
\hline 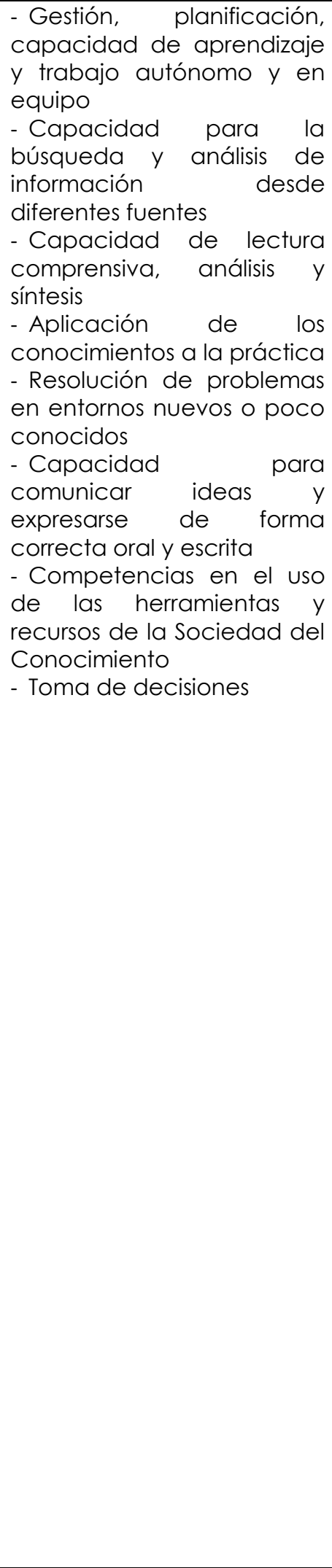 & 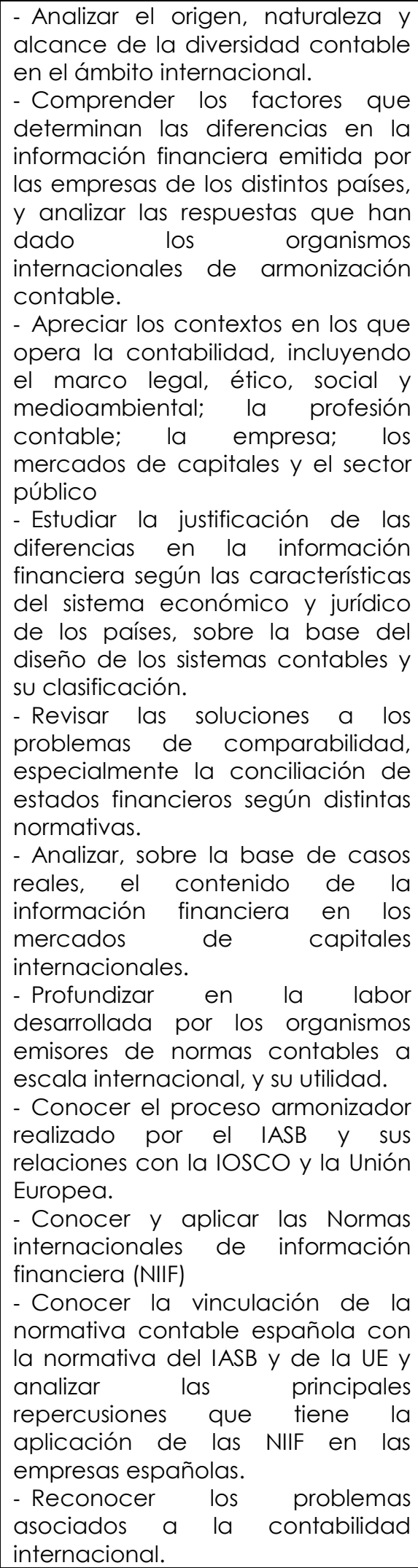 & $\begin{array}{l}\text { - Trabajo en equipo } \\
\text { - Razonamiento crítico de } \\
\text { - Capacidad de datos } \\
\text { interpretación de } \\
\text { financieros } \\
\text { - Compromiso ético } \\
\text { - Aprendizaje autónomo } \\
\text { - Iniciativa y espíritu } \\
\text { emprendedor }\end{array}$ \\
\hline
\end{tabular}


El conjunto de competencias señaladas en el apartado anterior condiciona el proceso de aprendizaje y las estrategias docentes potenciales. La búsqueda de que el estudiante, no sólo tenga unos conocimientos, sino que sea capaz de adaptarse a diferentes situaciones y solucione problemas reales con actitud crítica, no se logra exclusivamente con una única metodología docente. Adicionalmente a la lección magistral o a la resolución de casos prácticos, que han sido las metodologías tradicionales en la docencia contable, deben implementarse otras estrategias, como el trabajo en equipo o el uso de entornos virtuales de aprendizaje. Al respecto, la literatura suele mostrar que metodologías docentes más activas influyen en un aprendizaje más profundo y duradero (Pascual et al., 2011; Gandía y Montagud, 2011; Arquero et al., 2004), aumentando la satisfacción y motivación de los estudiantes, aunque no necesariamente llevan a unos mejores resultados académicos (Oliveras et al., 2013; Beltrán et al., 2011).

La amplitud y diversidad de metodologías docentes a aplicar con el fin de alcanzar las competencias propuestas se favorecen especialmente en los entornos virtuales de aprendizaje. Este tipo de entornos puede mejorar la calidad de la enseñanza y del aprendizaje (Durán et al. 2015), al permitir un enfoque de aprendizaje más centrado en el estudiante (Ballesteros et al., 2010; Wells et al., 2008), concediéndoles un papel más activo. De hecho, la tendencia es combinar las clases tradicionales con el uso de recursos virtuales. No obstante, en muchos casos, se quedan como una simple herramienta para la provisión de material a los alumnos, sin llegar a aprovechar todas las ventajas potenciales. A nivel internacional, la literatura ha mostrado que combinar las clases tradicionales con actividades virtuales puede afectar positivamente al rendimiento de los estudiantes (e.g. Boyle et al., 2009); sin embargo, otros autores (Durán et al. 2015) evidencian más su uso como una herramienta complementaria de apoyo a la docencia presencial, que es valorada positivamente por parte de los estudiantes, pero sin llegar a tener una influencia significativa sobre el rendimiento académico.

Conjuntamente con las actividades virtuales, el trabajo en equipo presenta una gran repercusión en la docencia contable, dado que posibilita alcanzar una de las competencias más demandadas por las empresas y los profesionales en la actuación de un contable (Arquero, 2000; Beltrán et al., 2011; Arquero y Tejero, 201 1; IFAC, 2008; Gómez-Ruiz y Naranjo-Gil, 2011). Esta metodología capacita para realizar actividades en común aprovechando el potencial de las relaciones interpersonales (Durán et al., 2013) e implica aprendizaje en tres terrenos específicos: conocimientos y cómo aplicarlos, habilidades, y valores y actitudes (Beltrán et al., 2011). Esta actividad permite al alumno profundizar en el conocimiento de los contenidos adquiridos en clase, aplicando estos a la búsqueda de soluciones ante nuevos problemas (Florez y Abelda, 2012). Diversos trabajos (Durán et al., 2013; Beltrán et al., 2011) argumentan su idoneidad como un adecuado complemento a la lección magistral y a las clases prácticas.

Con el trabajo en equipo se pretende alcanzar una serie de fines: potenciar el desarrollo de los hábitos de auto-planificación y gestión del tiempo; favorecer la interacción del alumno con los demás componentes del grupo; gestionar el liderazgo y la negociación; resolver conflictos, desarrollar habilidades de comunicación oral. Con ello, se facilita el desarrollo de la capacidad de expresión y de motivación a nivel individual y grupal (Beltrán et al., 2011), potenciando la productividad y permitiendo una mejor generalización del conocimiento.

Sin embargo, el grado de compromiso de los estudiantes implicados, sus criterios de organización del trabajo en equipo y la aparición de comportamientos oportunistas pueden condicionar el éxito de esta técnica didáctica. Por consiguiente, se ha subrayado la necesidad de un seguimiento minucioso de la actividad por parte del 
profesor, evaluando tanto el producto final como el proceso de consecución (MarínGarcía et al., 2008)

Su uso en asignaturas de empresa y, especialmente contabilidad, ha llevado a resultados no concluyentes. Mientras que Carrasco et al. (2009), Rodríguez Molinuevo (2010), Gómez-Ruiz y Naranjo-Gil (2010) o Florez y Abelda (2012), entre otros, evidencian un alto grado de satisfacción al implementar esta metodología, al mismo tiempo que desarrolla capacidades o competencias necesarias para un profesional de la actividad contable (Durán et al., 2013), otros estudios matizan los resultados obtenidos. En este sentido, Beltrán et al. (2011) encuentran que el trabajo en grupo no contribuyó definitivamente a mejorar las calificaciones de la asignatura de Contabilidad Financiera, aunque se percibe por parte los alumnos como una relevante ayuda a la docencia impartida a través de la lección magistral. En otras palabras, se consigue incrementar el atractivo del proceso de aprendizaje, pero no contribuye a mejorar la competencia tradicionalmente considerada más relevante, la relativa al conocimiento técnico de la materia. En la misma línea, Marín-García et al. (2008), en una asignatura de Administración de Empresas, obtienen que los grupos cuyo funcionamiento es adecuado, con un equilibrio idóneo en la participación de sus miembros, no son los que mejores informes finales entregan. Por tanto, se subraya la necesidad de haber adquirido previamente los conocimientos necesarios para que las intervenciones sean provechosas. En consecuencia, tal como constatan Arquero et al. (2011), algunos de los fundamentos de la metodología tradicional de la enseñanza enfocada en la transmisión de contenidos han permanecido en la configuración actual de la enseñanza por competencias, dado que parece evidente que herramientas tradicionales, como podría ser la lección magistral, siguen siendo, a pesar de todos los cambios, un vehículo idóneo de transmisión de conocimientos (Beltrán et al., 2011).

\section{SISTEMAS DE EVALUACIÓN}

Tal como indican Gómez-Ruiz y Naranjo-Gil (2011, p. 193) y Gandía y Montagud (2011), las innovaciones en los métodos docentes deben complementarse con nuevas herramientas de evaluación que permitan una evaluación integral, sistemática, permanente, reflexiva y recíproca, basada en competencias; es decir, que comprenda no sólo los conocimientos adquiridos, sino también el desarrollo de competencias y habilidades por parte de los estudiantes. En este contexto, se subraya especialmente la necesidad de que exista una fuerte vinculación entre lo que se pretende que el alumno aprenda y lo que realmente se está evaluando (Mingorance, 2008), con una coordinación plena entre metodología y sistema de evaluación.

En este sentido, la adaptación de los estudios al EEES, con su énfasis en la consecución de competencias, ha posibilitado un cambio en el sistema de evaluación, modificándose para poder valorar no sólo el aprendizaje de conocimientos de los estudiantes, sino también las competencias disciplinares y profesionales (Pascual et al., 2011), evaluando si los alumnos han sido capaces de adquirir y desarrollar las competencias necesarias para su futuro éxito profesional (Gómez-Ruiz y Naranjo-Gil, 2011). Tal como exponen Martí y Orgaz (2011 , p. 52), si se cambia la forma de enseñar, también ha de cambiarse la forma de evaluar, optándose por un sistema de 'opción formativa' en la que no sólo se evalúa el dominio de los contenidos de un temario por parte del estudiante, sino que además ha de evaluar y garantizar que los estudiantes sepan aplicar todo lo que han aprendido.

Diferentes estudios (ej. Fuertes et al., 2015; Benito y Cruz, 2005) han especificado diversas características que conducen a una mayor eficacia de la evaluación, como el ajuste a las competencias y a la realidad práctica, la provisión de feedback para su constante revisión y mejora, el involucramiento de los estudiantes en la evaluación, 
etc. En esta línea, Benito y Cruz (2005) señalan que el proceso de evaluación debe ser transparente, con unos criterios públicos y conocidos, y formativo, en el sentido de que proporcione una retroalimentación a profesores y alumnos, que así podrían ajustar su enseñanza o aprendizaje en función de la información recibida.

En el campo concreto de la contabilidad, la evaluación debería centrarse en comprobar que se han adquirido los conocimientos económico-financieros propios de la disciplina, que se han desarrollado las habilidades necesarias para el tratamiento de los datos y su comprensión, así como las competencias de trabajo en equipo, iniciativa y autoaprendizaje, entre otros aspectos (Garandillas et al., 2011; Beltrán et al., 2011). Con estos objetivos potenciales, Cottell y Harwood (1998) consideran que un proceso de evaluación continua consigue mejorar el aprendizaje efectivo de los estudiantes de contabilidad y puede sustituir los tradicionales mecanismos de evaluación a través de exámenes formales por escrito. En consecuencia, una evaluación continua potenciada por el uso de recursos virtuales (ej. realización de cuestionarios on-line) y exámenes parciales puede suponer un sistema idóneo para comprobar la adquisición de las competencias por parte de los estudiantes en materia contable, entre ellas las de trabajo en equipo, resolución de problemas y comunicación escrita. Este sistema permite la retroalimentación apropiada, posibilitando al alumno asimilar los contenidos de forma gradual, rectificar errores a tiempo y prepararse para el examen final; por su parte, el profesor conocerá las dificultades con las que se enfrenta el alumno y los progresos que está realizando, dispone de más información sobre la evolución de los estudiantes y los contenidos más problemáticos, y podría intervenir para mejorar y reorientar su aprendizaje en el caso de que no sea el adecuado (Mingorance, 2008; Fuertes et al., 2015).

La evaluación continua puede abarcar un rango amplio de actividades: participación activa en el aula y en seminarios, resolución de casos y/o ejercicios, realización y presentación de trabajos individuales o en grupo, exámenes parciales, examen final, etc. (Pascual et al., 2011). Por tanto, se valoran un conjunto de actividades que el alumno realiza para mejorar sus competencias, conjuntamente con un posible examen final que englobe todos los conocimientos adquiridos.

Buena parte de la literatura al respecto ha obtenido resultados positivos al implantar esquemas de evaluación continua. Algunos estudios analizan variables más perceptivas (por ejemplo, Garandillas et al., 2011; Mingorance, 2008), mostrando que la evaluación continua lleva a una mayor motivación y compromiso del estudiante con la asignatura (por ejemplo, aumenta el porcentaje de presentados sobre matriculados); el alumnado suele valorar positivamente esta forma de evaluación, evidenciando un alto grado de satisfacción. Por tanto, mejora su percepción y su actitud ante la asignatura, en comparación con otros sistemas tradicionales de evaluación.

Otros trabajos se centran directamente en el rendimiento académico, obteniendo un efecto positivo de la evaluación continua sobre el mismo (Gandía y Montagud, 201 1; Oliveras et al, 2013; Martí y Orgaz, 2014). En general, este sistema presenta un impacto positivo sobre el rendimiento, mejorando la calificación a los estudiantes. Por ejemplo, Durán et al. (2013) obtiene que las notas alcanzadas en las pruebas parciales tienen una influencia positiva y significativa sobre la probabilidad de aprobar el examen final, concluyendo que el estudio continuo que suele implicar esta forma de evaluación influye positivamente sobre el rendimiento final. No obstante, también puede limitar la obtención de calificaciones elevadas, puesto que es más difícil que el estudiante obtenga calificaciones sobresalientes en todas las actividades (en comparación con la evaluación a través de un único examen final). 
Las nuevas tecnologías permiten que diferentes actividades de la evaluación continua puedan realizarse a través de un entorno virtual, como los cuestionarios interactivos. Su aplicación a asignaturas de contabilidad ha mostrado su utilidad como herramienta efectiva para la adquisición de competencias por parte del estudiante. Martí y Orgaz (2011, 2014) subrayan su efectividad en asignaturas de carácter introductorio, perdiendo eficacia conforme aumenta la complejidad de la asignatura. Fuertes et al. (2015) enfatizan la gran aceptación de esta herramienta de evaluación por parte de los estudiantes, que la perciben como el elemento que más contribuye a su proceso de aprendizaje, por delante de los exámenes parciales. La mejora en el rendimiento académico como consecuencia de esta herramienta puede deberse a diversos factores: aumenta la motivación del alumno hacia la asignatura, le permite evaluar su progreso en el proceso de aprendizaje, asegurándose de que ha adquirido los conocimientos exigidos en el programa de la asignatura, o le permite desarrollar la capacidad para organizar y planificar su trabajo de forma autónoma.

\section{ANÁLISIS DE LA DOCENCIA EN LAS UNIVERSIDADES ESPAÑOLAS}

Tras exponer diversas propuestas en las metodologías docentes y en los sistemas de evaluación que se han producido como consecuencia de la implantación de los Grados en el EEES, con especial referencia a las asignaturas de contabilidad, a continuación se planteará la aplicación a la asignatura de Contabilidad Internacional. Esta asignatura de especialización se ha diseñado y configurado en los nuevos planes de estudio dentro de los esquemas del Espacio Europeo de Educación Superior. Por tanto, se trata de una asignatura en la que, desde el primer momento, pueden aplicarse las metodologías docentes y los sistemas de evaluación mencionados, que pueden permitir una consecución efectiva de las competencias a alcanzar (expuestas en el apartado 3).

Con el fin de analizar precisamente esta aplicación se ha procedido a revisar las Fichas Docentes publicadas en las páginas web de las universidades españolas para el curso 2016-2017, identificando aquellas relativas a Contabilidad Internacional. Seguidamente se describen los resultados del análisis, exponiendo una Visión panorámica entre universidades, Denominaciones y Titulaciones en las que se oferta, Tipología de la asignatura y peso cuantitativo, Disponibilidad de información, Metodologías docentes y Sistemas de evaluación.

\subsection{Visión panorámica entre Universidades}

El estudio se ha centrado en las universidades españolas, cuyo listado se encuentra disponible en la web de la Conferencia de Rectores de Universidades Españolas (CRUE). El conjunto estudiado se compone de 75 instituciones, 50 de ellas públicas y 25 privadas. De este conjunto inicial, se excluyó una universidad privada que no ofertaba estudios de empresa ni en Grado ni en Postgrado. La Tabla 2 recoge la información sobre la docencia de asignaturas de Contabilidad Internacional en el conjunto de las 74 Universidades.

Como puede apreciarse, 35 de estas 74 universidades (un 47,3\%) no oferta esta temática en sus Planes de Estudio ni en Grado ni en Postgrado, en forma de asignatura autónoma. Entre las 39 universidades que sí la ofrecen dentro de sus Planes de Estudio, 23 de ellas (59\%) la ofertan en Grado, 28 de ellas $(71,8 \%$ ) la incluyen como asignatura de Master y en 12 universidades $(30,8 \%)$ aparece tanto en Grado como en Postgrado. Adicionalmente, 6 universidades (15,4\%) la ofrecen simultáneamente en varios Grados y en 5 universidades $(12,8 \%)$ se imparte en varios títulos de Master. 
Tabla 2. Docencia de asignaturas de Contabilidad Internacional en universidades españolas

\begin{tabular}{|l|c|c|}
\hline & $\mathbf{N}^{\circ}$ de universidades & Porcentaje \\
\hline Sin docencia en Planes de Estudio & 35 & $47,3 \%$ \\
\hline Con docencia en Planes de Estudio & 39 & $52,7 \%$ \\
\hline & & $59 \%$ \\
\hline Docencia en Grado & 23 & $71,8 \%$ \\
\hline Docencia en Master & 28 & $30,8 \%$ \\
\hline $\begin{array}{l}\text { Docencia tanto en Grado como en } \\
\text { Master }\end{array}$ & 12 & $15,4 \%$ \\
\hline Docencia en varios Grados & 6 & $12,8 \%$ \\
\hline Docencia en varios Master & 5 & \multicolumn{2}{|c|}{} \\
\hline & 75 (1 sin docencia en materia empresarial) \\
\hline$N^{\circ}$ total de universidades &
\end{tabular}

En conclusión, a pesar de su creciente peso en la importancia de la Contabilidad, la docencia de Contabilidad Internacional en forma de asignatura independiente no se encuentra tan extendida dentro de la Universidad española, ni siquiera en forma de optativa. Aproximadamente la mitad de las universidades no la incluyen en sus Planes de Estudio, quedando, por tanto, muy alejada de la situación de otras asignaturas más clásicas de la temática contable, como Análisis Contable, Consolidación de Cuentas o Auditoría.

\subsection{Denominación y Titulaciones en las que se oferta}

La Tabla 3 recoge el número total de asignaturas de Contabilidad Internacional impartidas en las Universidades españolas, su oferta como parte de un Grado o de un Master, y las cuatro denominaciones más habituales.

Tabla 3. Asignaturas de Contabilidad Internacional en las universidades españolas

\begin{tabular}{|c|c|}
\hline \multicolumn{2}{|c|}{$\mathrm{N}^{\circ}$ de asignaturas ofertadas $=62$} \\
\hline Impartidas en Grado $=29$ & \\
\hline \multicolumn{2}{|c|}{ DENOMINACIONES MÁS HABITUALES } \\
\hline Contabilidad Internacional & 18 asignaturas \\
\hline Normas Internacionales de Información Financiera & 11 asignaturas \\
\hline Normas Internacionales de Contabilidad & 3 asignaturas \\
\hline Normativa Contable Internacional & 3 asignaturas \\
\hline
\end{tabular}

En total, las 39 universidades que disponen de la asignatura vinculada a la contabilidad internacional en sus Planes de Estudio ofertan 62 asignaturas, 29 en Grado y 33 en Master.

Del estudio de los nombres de las asignaturas, se identifican 27 denominaciones diferentes, siendo las más habituales las indicadas en la Tabla 3 , en la que encontramos una preferencia por una denominación clara y directa, Contabilidad Internacional o Normas Internacionales de Información Financiera, a gran distancia de otras denominaciones, como Normas Internacionales de Contabilidad o Normativa Contable Internacional. En consecuencia, tenemos una amplia dispersión en las restantes denominaciones, con 23 denominaciones diferentes, adicionales a las indicadas en la Tabla 3, que aparecen una o dos veces entre los Planes de Estudios de las universidades españolas.

La Tabla 4 expone los Grados en los que se recoge específicamente una asignatura de Contabilidad Internacional. En 9 universidades, la asignatura de Contabilidad Internacional se oferta en el Grado en Administración y Dirección de Empresas, siendo esta la opción mayoritaria. Las otras dos opciones más habituales suelen ser el Grado específico en Contabilidad y Finanzas ( 6 asignaturas) y el Grado en Economía (5 
asignaturas a nivel nacional). También se detecta la tendencia a impartirla, en algunas universidades, en perfiles más vinculados a la internacionalización o al comercio internacional.

Tabla 4. Grados en los que se imparte Contabilidad Internacional a nivel nacional

\begin{tabular}{|c|c|c|}
\hline DENOMINACIÓN DEL GRADO & No de asignaturas & Porcentaje \\
\hline Grado en Administración y Dirección de & 9 & 31,03 \\
Empresas & & \\
Grado en Administración y Dirección de & 1 & 3,45 \\
Empresas + Economía (Mención Finanzas) & 1 & 3,45 \\
Grado en Ciencias Empresariales - Management & 1 & 3,45 \\
Grado en Comercio Internacional & 1 & 3,45 \\
Grado en Comercio y Marketing & 5 & 17,24 \\
Grado en Economía & 2 & 6,90 \\
Grado en Economía y Negocios Internacionales & 1 & 3,45 \\
Grado en Empresa Internacional & 6 & 20,79 \\
Grado en Finanzas y Contabilidad & 1 & 3,45 \\
Grado en Gestión de Pequeñas y Medianas & 1 & 3,45 \\
Empresas & 100,00 \\
Grado en International Business Economics & 29 & $C 0,6 b i d a d$ \\
\hline
\end{tabular}

La denominación de los Master que contienen la asignatura de Contabilidad Internacional es mucho más variada. Del análisis de los Planes de Estudio, se identifican 29 denominaciones diferentes. En 13 denominaciones surge la vinculación con la Auditoría de Cuentas (ej: "Master Universitario en Auditoría de Cuentas", "Master Universitario en Contabilidad y Auditoría" o "Master Universitario en Contabilidad, Auditoría y Control de Gestión"), siendo parte de los programas impartidos para la formación teórica de los futuros auditores de cuentas. Al igual que en la docencia en Grado, se detecta también relación con cuestiones de internacionalización, como "Master de Internacionalización: Aspectos económicos, empresariales y jurídico-políticos", "Master en Dirección Empresarial desde la Innovación y la Internacionalización" o "Master en Internacionalización Económica: Gestión del Comercio Internacional".

\subsection{Tipología de la asignatura y peso cuantitativo}

La Tabla 5 recoge el carácter obligatorio u optativo de la asignatura dentro de los Planes de Estudios que contemplan su impartición y el número de créditos, diferenciando entre oferta en grado y en postgrado. En global (datos no presentados), se aprecia una ligera tendencia a ofertarla como asignatura optativa (52,5\% frente al 47,5\% que la considera como obligatoria en el respectivo Plan de Estudios). Sin embargo, se obtienen pautas diferentes en Grado y en Master.

En Grado, se oferta principalmente como asignatura optativa (22 asignaturas; $76 \%$ ) habitualmente de 6 ECTS. En cambio, la oferta en master suele considerarla como asignatura obligatoria (22 asignaturas; 69\%), con un peso más variable (desde una carga docente de 2 ECTS hasta 9 ECTS, con una carga media de aproximadamente 5 créditos y un valor más repetido de 3 
créditos). La diferente temática y configuración de los Master se traduce en una mayor variabilidad en su oferta.

Tabla 5. Tipología de la asignatura y peso cuantitativo

Panel A. Asignaturas en Grado

\begin{tabular}{|c|c|}
\hline \multicolumn{2}{|c|}{ TIPOLOGÍA } \\
\hline Obligatoria $=7$ asignaturas (24\%) & Optativa = 22 asignaturas (76\%) \\
\hline \multicolumn{3}{|c|}{ NÚMERO DE CRÉDITOS } \\
\hline Media & 5,83 ECTS \\
\hline Mínimo & 5 ECTS \\
\hline Máximo & 6 ECTS \\
\hline Moda & 6 ECTS \\
\hline \multicolumn{2}{|c|}{$N=29$ asignaturas } \\
\hline
\end{tabular}

\begin{tabular}{|c|c|} 
Panel B. Asignaturas en Master \\
\begin{tabular}{|c|c|}
\hline \multicolumn{2}{|c|}{ TIPOLOGÍA* } \\
\hline Obligatoria $=22$ asignaturas (69\%) & Optativa = 10 asignaturas (31\%) \\
\hline \multicolumn{2}{|c|}{ NÚMERO DE CRÉDITOS** } \\
\hline Media & 4,96 ECTS \\
\hline Mínimo & 2 ECTS \\
\hline Máximo & 9 ECTS \\
\hline Moda & 3 ECTS \\
\hline
\end{tabular}
\end{tabular}

* Se ha excluido 1 asignatura que no reporta la tipología

** Se han excluido 2 asignaturas que no indican el $n^{\circ}$ de créditos

Asimismo, de las 42 asignaturas que indican el número de profesores encargados de su docencia, en 18 de ellas $(42,8 \%)$ la asignatura se imparte por un único profesor, mientras que en 13 de ellas $(30,9 \%)$ la docencia incluye dos profesores.

6.4. Disponibilidad de información sobre metodologías docentes y sistemas de evaluación

Uno de los aspectos clave en el planteamiento de la asignatura en su Ficha Docente es la exposición de las metodologías docentes que se han diseñado y los sistemas de evaluación que se van a seguir. Sin embargo, muchas asignaturas no informan sobre las metodologías y la evaluación, o simplemente lo exponen de manera general, sin incluir un mayor nivel de desagregación cuantitativa, es decir, sin indicar cuál va a ser el peso de la metodología seguida o del sistema de evaluación planteado.

La Tabla 6 resume la difusión de información sobre metodologías docentes y sistemas de evaluación. El 77,4\% de las asignaturas indican cuáles van a ser las metodologías docentes que se van a seguir en la asignatura (ej: lección magistral o método expositivo, resolución de problemas, debates, etc.); sin embargo, sólo 28 asignaturas (el $45,2 \%$ ) profundizan en un mayor nivel de detalle, indicando el número de horas y, en consecuencia, el peso de cada una de las metodologías. Existe una mayoría de asignaturas en las que, aun indicando los métodos didácticos que se seguirán en la docencia, no se especifica de antemano al estudiante cuál va a ser la metodología más dominante o a qué forma didáctica se le va a prestar un mayor énfasis.

En lo que respecta a los sistemas de evaluación, el $82,3 \%$ de las asignaturas indican cuáles van a ser los sistemas a través de los cuales se va a evaluar el rendimiento del estudiante de la asignatura. Sin embargo, no todas las asignaturas indican el peso de cada una de las fuentes de evaluación, puesto que 15 de ellas $(24,2 \%)$ no señalan qué 
peso le va a corresponder en la calificación final. En consecuencia, en 47 asignaturas $(75,8 \%)$ se informa al estudiante en la Ficha Docente tanto de los mecanismos de evaluación como del porcentaje que cada uno de ellos va a suponer de cara al cómputo final de la evaluación.

Tabla 6. Suministro de información en la Ficha Docente sobre metodologías docentes y sistemas de evaluación ( $\mathrm{N}^{\circ}$ total de asignaturas $=62$ )

\begin{tabular}{|c|c|c|c|}
\hline \multirow{2}{*}{\multicolumn{2}{|c|}{$\begin{array}{l}\text { METODOLOGÍAS DOCENTES } \\
\text { INDICACIÓN DE INFORMACIÓN }\end{array}$}} & \multirow{2}{*}{\multicolumn{2}{|c|}{$\begin{array}{l}\text { SISTEMAS DE EVALUACIÓN } \\
\text { INDICACIÓN DE INFORMACIÓN }\end{array}$}} \\
\hline & & & \\
\hline $\begin{array}{c}\text { Indican = } \\
48 \text { asignaturas } \\
(77,4 \%)\end{array}$ & $\begin{array}{c}\text { No indican = } \\
14 \text { asignaturas } \\
(22,6 \%)\end{array}$ & $\begin{array}{c}\text { Indican = } \\
51 \text { asignaturas } \\
(82,3 \%)\end{array}$ & $\begin{array}{c}\text { No indican = } \\
11 \text { asignaturas } \\
(17,7 \%)\end{array}$ \\
\hline \multicolumn{2}{|c|}{ PESO DE LAS DISTINTAS METODOLOGÍAS } & \multicolumn{2}{|c|}{ PESO DE LOS DISTINTOS SISTEMAS } \\
\hline $\begin{array}{c}\text { Indican = } \\
28 \text { asignaturas } \\
(45,2 \%)\end{array}$ & $\begin{array}{c}\text { No indican = } \\
34 \text { asignaturas } \\
(54,8 \%)\end{array}$ & $\begin{array}{c}\text { Indican = } \\
47 \text { asignaturas } \\
(75,8 \%)\end{array}$ & $\begin{array}{c}\text { No indican = } \\
15 \text { asignaturas } \\
(24,2 \%)\end{array}$ \\
\hline
\end{tabular}

\subsection{Metodologías docentes}

La Tabla 7 nos informa de la diversidad y amplitud de metodologías docentes que se siguen en la docencia de la asignatura de Contabilidad Internacional en las universidades españolas.

Entre las 48 asignaturas que informan sobre las metodologías docentes que se van a emplear, existe una marcada preferencia por el método expositivo (42 asignaturas; $87,5 \%$ ), seguido de la resolución de casos prácticos (36 asignaturas; $75 \%$ ) y los trabajos en grupo (20 asignaturas; $41,7 \%$ ). A cierta distancia, se sitúan los debates o discusión dirigida (9 asignaturas; $18,8 \%$ ) y el estudio de casos, que la incluyen dentro de su repertorio docente únicamente 3 asignaturas (Tabla 7).

Tabla 7. Uso de metodologías docentes

\begin{tabular}{|c|c|c|}
\hline Metodología & $\begin{array}{c}N^{\circ} \text { de } \\
\text { asignaturas }\end{array}$ & Porcentaje \\
\hline Método Expositivo & 42 & $87,5 \%$ \\
\hline Resolución de ejercicios prácticos & 36 & $75 \%$ \\
\hline Trabajos en grupo & 20 & $41,7 \%$ \\
\hline Debates (discusión dirigida) & 9 & $18,8 \%$ \\
\hline Estudio de casos & 3 & $6,3 \%$ \\
\hline \multicolumn{3}{|l|}{$\mathrm{N}^{\circ}$ de metodologías seguidas } \\
\hline 1 método & 3 & $6,3 \%$ \\
\hline 2 métodos & 28 & $58,3 \%$ \\
\hline 3 métodos & 17 & $35,4 \%$ \\
\hline \multicolumn{3}{|c|}{ Combinaciones de metodologías más frecuentes } \\
\hline Método expositivo + Resolución de ejercicios prácticos & 16 & $33,3 \%$ \\
\hline Método expositivo + Trabajos en grupo & 5 & $10,4 \%$ \\
\hline Método expositivo + Estudio de casos & 2 & $4,2 \%$ \\
\hline Resolución de ejercicios prácticos + Trabajos en grupo & 2 & $4,2 \%$ \\
\hline $\begin{array}{l}\text { Método expositivo + Resolución de ejercicios prácticos + Trabajo } \\
\text { en grupo }\end{array}$ & 11 & $22,9 \%$ \\
\hline $\begin{array}{l}\text { Método expositivo + Resolución de ejercicios prácticos + } \\
\text { Debate }\end{array}$ & 5 & $10,4 \%$ \\
\hline
\end{tabular}


La mayor parte de las universidades utilizan, al menos, dos métodos didácticos entre los cinco contemplados en este estudio (58,33\% con 2 métodos; $35,4 \%$ con 3 métodos), que son básicamente el método expositivo y la resolución de problemas, dos de las metodologías didácticas tradicionales en la docencia de las asignaturas de temática contable. Entre las 48 asignaturas, 16 siguen una combinación de método expositivo y resolución de ejercicios, mientras que en 11 de ellas se combina además con la realización de trabajos en grupo.

La Tabla 8 indica, en primer lugar, el número de asignaturas que, utilizando una determinada metodología de acuerdo con su Ficha Docente, informan sobre el número de horas que implican dentro de la distribución de la asignatura. Una vez filtradas las asignaturas que reportan el peso cuantitativo de la metodología, se recoge el peso medio, mínimo y máximo que se le otorga.

Tabla 8. Peso cuantitativo de las diferentes metodologías didácticas

\begin{tabular}{|c|c|c|c|c|c|}
\hline Metodología & $\begin{array}{c}\mathrm{N}^{\circ} \text { de } \\
\text { asignaturas } \\
\text { que la utilizan }\end{array}$ & $\begin{array}{l}\quad N^{\circ} \text { de } \\
\text { asignaturas } \\
\text { que informan } \\
\text { sobre el peso } \\
\text { cuantitativo }\end{array}$ & $\begin{array}{c}\text { Peso mínimo } \\
(\%)\end{array}$ & $\begin{array}{c}\text { Peso máximo } \\
(\%)\end{array}$ & $\begin{array}{c}\text { Peso medio } \\
(\%)\end{array}$ \\
\hline $\begin{array}{l}\text { Método } \\
\text { expositivo }\end{array}$ & 42 & 24 & $5 \%$ & $100 \%$ & $46,17 \%$ \\
\hline $\begin{array}{l}\text { Resolución } \\
\text { de ejercicios } \\
\text { prácticos }\end{array}$ & 36 & 22 & $13 \%$ & $82 \%$ & $45,91 \%$ \\
\hline $\begin{array}{l}\text { Trabajos en } \\
\text { grupo }\end{array}$ & 20 & 8 & $8 \%$ & $40 \%$ & $23,88 \%$ \\
\hline $\begin{array}{l}\text { Debates } \\
\text { (discusión } \\
\text { dirigida) }\end{array}$ & 9 & 5 & $5 \%$ & $50 \%$ & $18,60 \%$ \\
\hline $\begin{array}{l}\text { Estudio de } \\
\text { casos }\end{array}$ & 3 & 0 & - & - & - \\
\hline \multicolumn{6}{|c|}{$\mathrm{N}^{\circ}$ total de asignaturas $=62$} \\
\hline
\end{tabular}

En relación a la Tabla 8, los resultados obtenidos confirman las tendencias mostradas en la Tabla 7, mostrando la importancia cuantitativa que supone, generalmente en número de horas, las dos principales metodologías docentes presentadas, esto es, el método expositivo y la resolución de problemas. La primera de ellas suele suponer en torno al $46 \%$ de la carga docente de la asignatura, oscilando entre un mínimo detectado del $5 \%$ y un máximo del $100 \%$, que implica que la asignatura se imparte exclusivamente utilizando lecciones magistrales. La otra metodología, cuantitativamente relevante, es la resolución de ejercicios, que suele implicar un porcentaje medio similar al método expositivo, aunque con una menor oscilación (entre el 13 y el $82 \%$ ). Los trabajos en grupo implican un peso mínimo del $8 \%$ en aquellas asignaturas que lo utilizan explícitamente, y un peso máximo del $40 \%$, con lo que el peso complementario hasta el $100 \%$ ha de completarse con técnicas didácticas más tradicionales. Una situación similar puede deducirse también para la metodología de los debates o discusión dirigida.

Adicionalmente al uso de metodologías clásicas de enseñanza en materia contable, podemos considerar que existe una tendencia a complementarlas con otras modalidades que impliquen un aprendizaje más colaborativo. Es habitual encontrar entre las Fichas Docentes pronunciamientos indicando que se fomentará la participación activa de los estudiantes, generando debates en el aula, exposiciones, 
etc. Entre otras, se mencionan puntualmente las siguientes metodologías en la docencia de Contabilidad Internacional:

- Análisis de fuentes documentales (con un peso del 10\%)

- Lecturas (con un peso del 15\%)

- Prácticas de ordenador (con un peso del 50\%)

- Presentaciones orales de temas y casos, ejercicios y trabajos

- Seminarios, especialmente sobre temas más complejos, como los instrumentos financieros, con un peso que puede alcanzar el $50 \%$

- Tutorías, con carácter presencial, siendo grupales en varias asignaturas, con una carga docente que oscila entre el $3 \%$ y el $15 \%$

\subsection{Sistemas de evaluación}

Entre las 51 asignaturas cuya información sobre sistemas de evaluación se recoge en sus respectivas Guías Docentes, se observa que el examen final sigue siendo la prueba de evaluación predominante de cara a medir el rendimiento del alumno en la asignatura, con un 92,2\% (Tabla 9). Sin embargo, es muy reducido el número de asignaturas a nivel nacional en las que existe una única fuente de evaluación (un $7,8 \%$ ). Aproximadamente el $90 \%$ de las asignaturas ofertadas incluyen, al menos, otro sistema de evaluación adicional. Entre estos, se detecta una marcada preferencia por los trabajos individuales (52,9\%) y por sistemas de evaluación continua basados en exámenes parciales (49\%). En consecuencia, se muestra un amplio uso de diferentes metodologías de evaluación, aunque el examen final se mantiene como una constante entre las diferentes asignaturas ofertadas por las universidades españolas.

Tabla 9. Sistemas de evaluación empleados

\begin{tabular}{|l|c|c|}
\hline Sistemas & $\mathrm{N}^{\circ}$ de asignaturas & Porcentaje \\
\hline Examen final & 47 & $92,2 \%$ \\
\hline Evaluación continua con exámenes parciales & 25 & $49,0 \%$ \\
\hline Trabajos en grupo & 20 & $39,2 \%$ \\
\hline Trabajos individuales & 27 & $52,9 \%$ \\
\hline Asistencia y participación & 14 & $27,5 \%$ \\
\hline & & \\
\hline$N^{\circ}$ de sistemas empleados & 4 & \\
\hline 1 sistema & 20 & $7,8 \%$ \\
\hline 2 sistemas & 20 & $39,2 \%$ \\
\hline 3 sistemas & 6 & $11,2 \%$ \\
\hline 4 sistemas & 1 & $2,0 \%$ \\
\hline 5 sistemas & & \\
\hline
\end{tabular}

La Tabla 10 muestra, en primer lugar, cuántas de las asignaturas ofertadas indican, no sólo el sistema específico empleado, sino el peso que va a tener este sistema de cara a la calificación final de la asignatura. Por ejemplo, no en todas las asignaturas en las que se indica que la evaluación se va a realizar a través de un examen final (47 asignaturas) informan además sobre el peso que va a tener este examen (42 asignaturas; es decir, 5 asignaturas simplemente reportan que se evaluará a través de un examen final, sin indicar en la Ficha Docente cuál será su peso).

Como se aprecia a partir de la Tabla 10, el peso de la evaluación recae principalmente en un examen de carácter escrito, sea a través de un examen final (con un peso medio del $59 \%$ en la calificación final, llegando en algún caso al 100\%) o a través de exámenes parciales (peso medio del $41,2 \%$ ). Paralelamente a lo observado en la Tabla 9, mientras que el examen final sigue siendo un sistema de evaluación recurrente en prácticamente la totalidad de las asignaturas, su peso suele 
complementarse con la evaluación que ofrecen otras fuentes de análisis del rendimiento del estudiante, en especial, a través de la realización de pruebas parciales, trabajos individuales $(37,7 \%)$ y trabajos en grupo $(33,2 \%)$. Destacan asimismo la amplia dispersión en el valor asignado al examen final (que oscila entre un mínimo del $20 \%$ y un máximo del $100 \%$ de la calificación final) y a los trabajos individuales (entre el $10 \%$ y el $75 \%$ de la evaluación global de la asignatura). En consecuencia, los sistemas de evaluación de esta asignatura, en el marco de los Grados que surgen a raíz de las reformas del EEES, no descansan únicamente en una única prueba de carácter final, sistema habitual de la evaluación del rendimiento del estudiante en las Licenciaturas previas, sino que buscan complementarla con diferentes fuentes, con una evaluación continua a través de pruebas parciales a lo largo del periodo de docencia y de trabajos, generalmente de carácter individual, realizados por los alumnos.

Tabla 10. Peso cuantitativo de los diferentes sistemas de evaluación

\begin{tabular}{|l|c|c|c|c|c|}
\hline Metodología & $\begin{array}{c}N^{\circ} \text { de } \\
\text { asignaturas } \\
\text { que lo utilizan }\end{array}$ & $\begin{array}{c}\mathrm{N}^{\circ} \text { de } \\
\text { asignaturas } \\
\text { que informan } \\
\text { sobre el peso } \\
\text { cuantitativo }\end{array}$ & $\begin{array}{c}\text { Peso mínimo } \\
(\%)\end{array}$ & $\begin{array}{c}\text { Peso máximo } \\
(\%)\end{array}$ & $\begin{array}{c}\text { Peso medio } \\
\text { (\%) }\end{array}$ \\
\hline Examen final & 47 & 42 & $20 \%$ & $100 \%$ & $59 \%$ \\
\hline $\begin{array}{l}\text { Evaluación } \\
\text { continua con } \\
\text { exámenes } \\
\text { parciales }\end{array}$ & 25 & 21 & $20 \%$ & $80 \%$ & $41,2 \%$ \\
\hline $\begin{array}{l}\text { Trabajos en } \\
\text { grupo }\end{array}$ & 20 & 14 & $10 \%$ & $50 \%$ & $33,2 \%$ \\
\hline $\begin{array}{l}\text { Trabajos } \\
\text { individuales }\end{array}$ & 27 & 21 & $10 \%$ & $75 \%$ & $37,7 \%$ \\
\hline $\begin{array}{l}\text { Asistencia y } \\
\text { participación }\end{array}$ & 14 & 7 & $10 \%$ & $30 \%$ & $21,4 \%$ \\
\hline
\end{tabular}

Al analizar los diferentes sistemas de evaluación, se detectan varios aspectos habituales:

- Establecer una amplia horquilla en el peso de los sistemas (por ejemplo, indicando que los exámenes tendrán una valoración entre el 50 y el 70\%)

- Un trabajo recurrente es el análisis de una Norma Internacional de Contabilidad (NIC o NIIF), sea de forma individual o en grupo

- En varias universidades se establece un doble sistema de evaluación, a elección del estudiante: uno basado en una evaluación continua y otro basado en el examen final; no obstante, en el primero de ellos suele ser habitual exigir un examen final, aunque con un peso reducido sobre la calificación final de la asignatura

- Las pruebas parciales, en las que, entre otras, se basa la evaluación continua, se realizan muchas veces forma de cuestionarios; sin embargo, el examen final suele establecerse en un formato de desarrollo, con contenido tanto teórico como práctico.

\section{DISCUSIÓN DE RESULTADOS}

La visión panorámica efectuada sobre la docencia de la asignatura de Contabilidad Internacional entre las universidades españolas permite extraer una serie de implicaciones y de conclusiones. En primer lugar, sorprende el elevado porcentaje de las universidades (en torno al $47 \%$ ) que no la ofertan como asignatura individual dentro de los Planes de Estudio de Grado ni de Postgrado. En torno al 53\% de las universidades ofertan la asignatura. Esta cifra es relativamente similar a los porcentajes mostrados en 
el trabajo de Stolowy y Tenenhaus (1998) para el caso español $(53,8 \%)$, aunque cabe subrayar que este último estudio se basa en un cuestionario, al que contestaron 13 universidades españolas, y en el que es factible un sesgo de pre-selección (esto es, que contestaran mayoritariamente aquellas universidades que incluían la contabilidad internacional en su oferta académica), además de que en la fecha de realización (1997-1998), la normativa IASB no tenía la relevancia que presenta en el actualidad. Asumiendo el dato expuesto por Stolowy y Tenehaus (1998), no ha habido un incremento en la oferta en los últimos veinte años.

Dado el peso creciente de la Contabilidad Internacional, de su importancia para los campos de la consolidación contable y la auditoría, así como para la internacionalización de las empresas, consideramos que se está omitiendo un importante aspecto en la formación contable de los futuros profesionales, habida cuenta de las tendencias en la educación en contabilidad (DeWet y Van Niekerk, 2001; Stolowy y Tenenhaus, 1998). Es especialmente llamativa esta omisión en el curriculum de formación contable en aquellos Grados que tienen una vocación más especializada, como el Grado en Finanzas y Contabilidad. Aquellas universidades que incluyen su docencia tienen una ligera preferencia por su impartición dentro de los títulos de Master, mientras que aproximadamente un tercio de las universidades oferentes la incluyen tanto en Grado como en Master. Por tanto, suele considerarse como una asignatura muy específica de formación muy avanzada, acorde con los resultados obtenidos por Arquero et al. (2009), que evidencian un escaso apoyo por parte de los egresados a incluirla como materia en el curriculum, debido a que se considera escasamente importante $y$, en todo caso, susceptibles de incluirse más como asignatura de postgrado. Esta menor importancia percibida posiblemente tenga su explicación en que buena parte del tejido empresarial está compuesta por pequeñas y medianas empresas, para las que estas normas no son tan relevantes. En este contexto, cabe su ubicación como materia de postgrado, para aquellos estudiantes que deseen enfocar su carrera profesional hacia la auditoría y la esfera internacional, en las cuales la docencia de esta materia cobra más sentido. Es decir, a la luz de estudios como Adhikari et al. (1999) o Adams y Roberts (1994), es preferible destinar la educación contable a nivel de grado a las cuestiones más técnicas y a las competencias de conocimiento más generales, y dejar la profundización para títulos de postgrado.

En segundo lugar, es destacable el aspecto relativo a la disponibilidad de la información. Muchas Fichas Docentes de las asignaturas de Contabilidad Internacional no informan sobre las metodologías y la evaluación $(22,6 \%$ no informan de las metodologías, $17,7 \%$ no informan de los sistemas de evaluación), o simplemente lo exponen de manera muy general, sin indicar el peso de las metodologías (por ejemplo, en número de horas) o de los diferentes sistemas de evaluación. Las comisiones de evaluación y seguimiento de los títulos suelen realizar especial hincapié en la provisión de una información suficiente al estudiante, lo cual no parece cumplirse en varias Fichas Docentes de esta asignatura. Este hecho es especialmente relevante en el campo de la evaluación, dado que entre los requisitos que los sistemas de evaluación deben reunir para ser efectivos se encuentra la transparencia (Benito y Cruz, 2005), materializada en unos criterios de evaluación públicamente conocidos de antemano.

En lo que respecta a las metodologías docentes, se ha subrayado por parte de la literatura previa que, más allá de la transferencia de conocimientos técnicos, los programas docentes en contabilidad internacional necesitan adaptar su enfoque pedagógico para asistir a los estudiantes con el desarrollo de las habilidades analíticas para realizar juicios y de síntesis (Coetze y Schmulian, 2012; Bonnier et al., 2013). Uno de los aspectos más positivos a destacar está relacionado con la amplitud y variedad de 
metodologías aplicadas por las universidades españolas, ya que únicamente el 6,3\% de las asignaturas se basan en una sola metodología; lo habitual es al menos utilizar 2 métodos. La amplitud de metodologías permite abarcar mejor el rango de competencias a alcanzar, tanto las genéricas vinculadas a la transmisión de conocimientos (que puede abordarse apropiadamente con el método expositivo) como las específicas y las transversales. El método expositivo y la resolución de problemas siguen siendo las metodologías habituales en la docencia contable, en lo relativo a esta asignatura, con un uso por parte del $87,5 \%$ y del $75 \%$ de las asignaturas, respectivamente. En cambio, el trabajo en grupo se utiliza por un $41,7 \%$ de las asignaturas, sin llegar a los niveles alcanzados por las otras metodologías. En este sentido, el trabajo en grupo suele reconocerse como una metodología especialmente idónea para alcanzar competencias específicas y transversales fundamentales en la formación del profesional contable, como la capacidad de trabajo en equipo, la resolución de problemas no programados y la comunicación oral y escrita (Durán et al., 2013; Beltrán et al., 2011; Gómez-Ruiz y Naranjo-Gil, 2011). Ciertamente suele argumentarse su uso como complemento al método expositivo o la resolución de problemas; sin embargo, un porcentaje de utilización del $40 \%$, con un peso medio del $24 \%$ en la distribución entre las diversas metodologías, parece excesivamente reducido, y puede limitar el desarrollo de estas competencias mencionadas.

A la vista de los resultados, el método expositivo o lección magistral aún detenta un 'protagonismo docente' reseñable, con un peso medio del $46,17 \%$ de la distribución de la asignatura. Esta tendencia marca diferencias con la docencia en otros países, en los cuales los estudios de casos suelen ser la herramienta docencia más habitual (Bonnier et al., 2013; Nelson y Salotti, 2013; Jackling, 2013; Munter y Reckers, 2009; Needles, 2010). Esta metodología permite exponer a los estudiantes a escenarios internacionales que proporcionen una experiencia con diferentes marcos regulatorios y de aplicación, y que aumente su familiaridad con los estados financieros preparados de acuerdo con las IFRS (Larson y Street, 2011), mostrando problemas contables reales y sus impactos desde diferentes perspectivas.

En relación a los sistemas de evaluación, la revisión efectuada detecta un predominio del examen final, con un $92,2 \%$ de asignaturas que lo aplican, con una horquilla de valoración entre el $20 \%$ y el $100 \%$. No obstante, y de forma similar a lo descrito para las metodologías, se aprecia una mayor variedad de herramientas de evaluación. Solamente 4 asignaturas $(7,8 \%)$ siguen un único sistema, mientras que aproximadamente el $90 \%$ de las asignaturas de Contabilidad Internacional basan su calificación en dos o tres sistemas. La siguiente herramienta más utilizada es la elaboración de trabajos individuales (52,9\% de las asignaturas), que permite centrarse en la búsqueda de información, razonamiento crítico, capacidad de comunicación. Entre el recurso al trabajo individual o al trabajo en grupo, se prefiere optar por el primero de ellos $(52,9 \%$ frente al $39,2 \%)$, con un mayor peso del mismo $(37,7 \%$ frente al 33,2\%; Tabla 10). Parece intuirse, a raíz de los datos, una mayor reticencia a la formación de grupos para realizar trabajos. Ello encaja con las observaciones de Beltrán et al. (2011), al subrayar que puede existir resistencia por parte de los estudiantes, ya que no están habituados a esta forma de trabajar, por lo que se sienten desorientados o porque consideran que estas actividades les obligan a invertir mucho tiempo. Sin embargo, es preciso resaltar la relevancia de las competencias alcanzables por el trabajo en grupo que no son fácilmente asimilables al trabajo individual, como la gestión del equipo, el liderazgo, la valoración de opiniones ajenas, etc.

El uso de exámenes parciales como herramienta de evaluación continua constituye el tercer sistema más utilizado de cara a la evaluación, con un $49 \%$ de asignaturas que han optado por él, oscilando en una horquilla entre el $20 \%$ y el $80 \%$ de la calificación 
final. Complementado con los trabajos individuales, muestra el importante peso de la evaluación continua, aunque, de acuerdo con las ventajas argumentadas por los estudios previos (Pascual et al., 2011; Fuertes et al., 2015; Gandía y Montagud, 2011), era esperable un mayor uso dentro de las asignaturas, superior al $49 \%$ detectado.

En conclusión, cabe resaltar el escaso peso que mantiene esta materia en las titulaciones ofertadas por las universidades españolas. Arquero et al. (2009) muestran que la contabilidad internacional tiene un bajo nivel de importancia percibida por parte de los egresados, probablemente como consecuencia de que la demanda laboral en España se centra mayoritariamente en pymes, para las cuales la normativa internacional no es especialmente relevante. En este sentido, tendría una mejor cabida en titulaciones de postgrado, en las que el estudiante busque una especialización contable, profundizando en la temática internacional, entre otros aspectos. Desde la perspectiva institucional de las universidades, es probable que el curriculum contable a nivel de grado alcance niveles de saturación que impida incorporar asignaturas nuevas (al menos, de carácter obligatorio), en línea con lo argumentado por Adhikari et al. (1999). Desde el punto de vista del profesorado, la docencia de contabilidad internacional constituye un fuerte desafío: es una materia que requiere mucho estudio y actualización constante, sin que ese trabajo muchas veces pueda servir para cuestiones de investigación. A la falta de experiencia profesional concreta en esta materia, se suma la falta de manuales y de recursos didácticos (Coetze y Schmulian, 2013; Jackling, 2013; Zhu et al., 2011), en comparación con otras asignaturas de naturaleza contable. La metodología docente a seguir exige un alto nivel de preparación, dado que el desarrollo de las capacidades de análisis y juicio a alcanzar por parte del alumno difícilmente se consigue con una única metodología. En consecuencia, si se juntan los factores de demanda con las dificultades por parte de la oferta, es entendible este menor peso mostrado por parte de la contabilidad internacional en los planes de estudio. No obstante, de acuerdo con Barth (2008) y Ashcroft et al. (2008), la contabilidad internacional es cada vez más importante dentro de la práctica contable y, por tanto, del curriculum contable, conforme el mundo se ha vuelto más interconectado políticamente y económicamente. Los profesionales contables han de tratar cada vez más con cuestiones de contabilidad internacional, especialmente en el campo de la auditoría, la consolidación de cuentas y el análisis económico-financiero. Sin duda, entre los eventos clave de los últimos años, la aceptación de las IFRS para el reporting financiero en muchos países motiva que la contabilidad internacional sea un área en el que todos los estudiantes de contabilidad han de tener, al menos, unas nociones introductorias.

\section{CONCLUSIONES}

La adaptación al EEES y la reforma de las titulaciones han supuesto una reformulación de las metodologías docentes. El enfoque hacia las competencias a conseguir, más que sobre los conocimientos a adquirir, ha cambiado el paradigma de la docencia, centrándose en un papel más activo del estudiante, al que deben dotarse de herramientas de autoaprendizaje y de aprendizaje a lo largo de la vida. De forma simultánea, deben transformarse los sistemas de evaluación, ampliándolos de manera que puedan valorarse diferentes competencias.

En lo que respecta a la educación en contabilidad, profesionales, empresas e instituciones han subrayado diversas carencias que se producían en las anteriores Licenciaturas, así como un conjunto de competencias no técnicas cuyo desarrollo ha de encomendarse a la educación superior, como el trabajo en equipo, las capacidades de comunicación y de resolución de problemas. Las herramientas tradicionales de la docencia en contabilidad, como el método expositivo o la resolución de ejercicios prácticos, o los sistemas de evaluación, muy habitualmente 
basados en un examen final, no parecen ser suficientes para alcanzar estas competencias. En este contexto, la reforma de las titulaciones con la adopción de los nuevos Grados ha permitido replantear las estrategias docentes, extendiéndolas a un rango mucho más amplio y diverso, que abarcaría desde el método expositivo hasta el trabajo en equipo, con la posibilidad de utilizar entornos virtuales de aprendizaje. Por otra parte, los sistemas de evaluación han de acompasarse a las metodologías seguidas, y enfocarse hacia la evaluación de competencias.

Asimismo, a las asignaturas clásicas de materia contable, se suma ahora la Contabilidad Internacional, cuyo peso en el campo empresarial es cada vez mayor. Además, se trata de una normativa con un alto grado de juicio y sofisticación, por lo que requiere el desarrollo de unas competencias de razonamiento crítico, de resolución de problemas no estructurados en el contexto de equipos de trabajo. La adopción de los nuevos Grados y la configuración de sus Planes de Estudio han permitido revisar su docencia en aquellas universidades en las que ya existían y, en aquellas que no la ofertaban, incorporarlas a la docencia ofertada por las universidades españolas, en forma de asignatura individualizada. Su diseño no viene lastrado por la docencia en anteriores titulaciones, sino que ha podido configurarse plenamente y de forma original en las estrategias docentes y en los sistemas de evaluación sugeridos como más idóneos para alcanzar las competencias definidas.

El presente estudio ha realizado una revisión de su docencia entre las universidades españolas, describiendo las principales metodologías propuestas y los sistemas de evaluación seguidos. Para ello, se han analizado las Fichas docentes de las asignaturas de Contabilidad Internacional ofertadas entre las 75 universidades españolas, tal como han sido publicadas en las páginas web de las titulaciones de Grado y de Postgrado.

Su estudio ha permitido extraer una serie de conclusiones. Por una parte, se observa una importante omisión de esta asignatura en numerosas universidades (un $47 \%$ aproximadamente), lo cual supone una merma reseñable en la formación contable del fututo profesional. Actualmente, es imprescindible el conocimiento de Contabilidad Internacional para una adecuada comprensión y aplicación de la consolidación de cuentas y de la auditoría. Esta omisión es aún más sorprendente en aquellos Grados más especializados (y menos generalistas que un Grado en Administración y Dirección de Empresas). Por otra parte, se detecta una falta de disponibilidad de información en las Fichas Docentes, puesto que en muchas asignaturas no se informa sobre las metodologías que se van a seguir o sobre los sistemas de evaluación que se van a plantear, o se expone de manera excesivamente genérica, sin llegar a cuantificar su peso. Ello afecta a la calidad de la actividad docente, de acuerdo con los estándares de evaluación y seguimiento de los Grados. Por consiguiente, dada la importancia de la asignatura en el curriculum contable, cabe destacar la necesidad de que se potencie su oferta en las universidades españolas, al menos a nivel de postgrado, y que, en aquellas que la imparten, se ofrezca una información completa que le guíe al alumno en su proceso de aprendizaje.

El análisis de las Fichas docentes ha permitido detectar una mayor variedad en las metodologías docentes seguidas, en comparación con las anteriores Licenciaturas. La lección magistral o método expositivo sigue teniendo un papel protagonista en la docencia en contabilidad, pero más del $90 \%$ de las asignaturas impartidas a nivel nacional emplean al menos otra metodología complementaria. No obstante, el trabajo en equipo, una de las metodologías con mayor impacto para alcanzar las competencias señaladas, aún se utiliza de forma más limitada, sin llegar a ser utilizada por la mitad de las asignaturas ofertadas $(41,7 \%)$. Por tanto, aún cabe mucha más posibilidad de uso de esta herramienta en la universidad española en lo que respecta a la asignatura de Contabilidad Internacional. Por otra parte, se detecta una escasa 
presencia del estudio de casos, que suele ser la metodología más sugerida a nivel internacional para la docencia de esta materia.

Simultáneamente, los sistemas de evaluación han ampliado su variedad, aunque sigue utilizándose el examen final de forma intensa ( $92 \%$ de las asignaturas ofertadas). Los trabajos individuales $(52,9 \%)$ y la evaluación continua basada en exámenes parciales $(49 \%)$ son las otras herramientas más utilizadas. Se evidencia una mayor tendencia al uso de los trabajos individuales frente a los trabajos en grupo. Nuevamente, se observa la necesidad de potenciar este tipo de trabajos, de cara a adquirir las competencias indicadas. Asimismo, cabe destacar que aún queda espacio para un mayor uso de la evaluación continua, cuyo planteamiento puede servir mejor para evaluar las competencias.

Este análisis presenta diferentes limitaciones, que constituirán futuras líneas de mejora y de investigación futura. En primer lugar, no se ha analizado la posible docencia de Contabilidad Internacional siguiendo un enfoque de integración, es decir, como parte del temario de otras asignaturas de materia contable. Se ha procedido de la manera expuesta porque se considera que la importancia actual de la Contabilidad Internacional puede justificar su docencia como asignatura específica, como ha ocurrido en otros países. Sin embargo, cabe reseñar que en muchas universidades se incluyen temas introductorios a la normativa IFRS en los programas de Contabilidad Financiera. En segundo lugar, no se profundiza en por qué los equipos docentes han optado por unas metodologías y sistemas de evaluación, en detrimento de otros. La elección de la estrategia docente es un proceso complejo en el que intervienen numerosas variables personales, institucionales y contextuales, cuyo estudio puede aportar información de interés. En tercer lugar, sería también oportuno analizar el impacto de las metodologías y de los sistemas de evaluación sobre la satisfacción de los estudiantes al cursar Contabilidad Internacional y sobre el rendimiento final, entendiendo rendimiento no sólo en términos de la calificación final sino de la adquisición completa de competencias y de interés en esta materia de tanta relevancia para la educación futura en contabilidad.

\section{BIBLIOGRAFÍA}

ADAMS. C. Y C. ROBERTS [1994]: International accounting education in the UK. Accounting Education, vol. 3, núm. 2: 167-181.

ADHIKARI, A., FLANIGAN, M. y R. TONDKAR [1999]: A survey of international accounting education in the US and some other countries. Journal of Accounting Education, vol. 17: 175-189.

AGENCIA NACIONAL DE EVALUACIÓN DE LA CALIDAD Y ACREDITACIÓN [2005]: Libro Blanco del título de grado en economía y en empresa. ANECA.

AICPA (American Institute of Certified Public Accountants) [1992]: Academic Preparation to Become a Certified Public Accountant. AICPA, Junio.

ARQUERO, J.L., DONOSO, J A., JIMÉNEZ, S.M. y J.M. GONZÁLEZ [2009]: Análisis exploratorio del perfil demandado para administración y dirección de empresas: implicaciones para el área contable. Spanish Accounting Review Revista de Contabilidad, vol. 12, núm. 2: 181-213.

ARQUERO J.L., JIMÉNEZ, S.M y J. JOYCE [2004]: Skills development, motivation and learning in financial statement analysis: an evaluation of alternative types of case studies. Accounting Education, vol. 13, núm 2: 191-212.

ARQUERO, J.L. [2000]: Capacidades no técnicas en el perfil profesional en contabilidad: las opiniones de docentes y profesionales. Revista Española de Financiación y Contabilidad, vol. 29, núm. 103: 149-172

ARQUERO, J.L. Y C. TEJERO [2011]: How well adapted are accounting students for Bologna? A comparative analysis of learning styles of Spanish social sciences 
students. Revista de Educación en Contabilidad, Finanzas y Administración de Empresas, núm. 2: 145-156.

ASHCROFT, P., CHEVIS, G. y L.M. SMITH [2008]: Faculty perspectives on international accounting topics. Advances in Accounting, incorporating Advances in International Accounting, vol. 24: 139-144.

BALLESTEROS, C., CABERO, J., LLORENTE, M.C. y J.A. MORALES [2010]: Usos del e-learning en las universidades andaluzas: estado de la situación y análisis de buenas prácticas. Revista de Medios y Educación, vol. 37: 7-18.

BARTH, M. [2008]: Global financial reporting: Implications for U.S. academics. Accounting Review, vol. 83, núm 5: 1159.1179.

BELTRÁN, J.L., PEREIRA, J.M. y J.L. SÁEZ [2011]: Aplicación práctica de técnicas docentes para Contabilidad Financiera. Revista de Educación en Contabilidad, Finanzas y Administración de Empresas, núm. 2: 3-34.

BENITO, A. y A. CRUZ [2005]: Nuevas claves para la Docencia Universitaria. Narcea.

BONNIER, C., DEMERENS, F., HOSSFELD, C. y A. LE MANH [2013]: A French Experience of an IFRS Transition. Issues in Accounting Education, vol. 28, núm. 2: 221-234

BOYLE, T., BRADLEY, C., CHALK, P., JONES, R., y P. PICKARD [2003]: Using blended learning to improve student success rates in learning to program. Journal of Educational Media, vol. 28, núm. 2-3: 165-178.

BUNK, G.P. [1994]. La transmisión de las competencias en la formación y perfeccionamiento profesionales de la RFA. Revista Europea Formación Profesional, núm 1: 8-14.

CALDERÓN, H., CASASÚS., T. y J.F. MARTíNEZ [2013]: De la Licenciatura al Grado en Administración y Dirección de Empresas: un análisis comparativo desde las necesidades de las empresas. Revista de Educación en Contabilidad, Finanzas y Administración de Empresas, núm. 4: 56-76.

CARRASCO, A., DONOSO, J.A., DUARTE, T., HERNÁNDEZ, J.J., LÓPEZ, R. Y C. NÚÑEZ [2009]: Aprendizaje basado en proyectos versus aprendizaje basado en actividades: Una experiencia en la elaboración y análisis de los estados financieros. La formación en contabilidad en los grados y másters. VI Jornadas de Docencia en Contabilidad. ASEPUC, Sevilla.

COETZE, S. y A. SCHMULIAN [2013]: The Effect of IFRS Adoption on Financial Reporting Pedagogy in South Africa. Issues in Accounting Education, vol. 28, núm. 2: 243251.

CONOVER, T., SALTER, S., y J. PRICE [1994]: International accounting education: A comparison of course syllabi and CFO preferences. Issues in Accounting Education, vol. 9, núm. 2: 259-270.

COTTELL, P. G. y E.M. HARWOOD [1998]: Using classroom assessment techniques to improve student learning in accounting classes. Issues in accounting education, vol. 13, núm. 3: 551-564.

DE WET, J.H. y M.C. VAN NIEKERK [2001]: An innovative approach to accounting education at the first-year level. Meditari Accountancy Research, vol. 9: 93-108.

DURÁN, P., MASIDE, J.M., CANTORNA, S. y D. RODEIRO [2013]: ¿Es el nuevo sistema de evaluación del EEES realmente diferente del sistema tradicional? Un análisis empírico del rendimiento académico en una asignatura de contabilidad. Revista de Educación en Contabilidad, Finanzas y Administración de Empresas, núm. 4: 77-96.

DURÁN, P., MASIDE, J.M., RODEIRO, D. y S. CANTORNA [2015]: Rendimiento académico y utilización de entornos virtuales de aprendizaje por los alumnos de una 
asignatura de contabilidad. Revista de Educación en Contabilidad, Finanzas y Administración de Empresas, núm. 6: 5-21.

ESCOBAR, B. Y S.M. JIMÉNEZ [2009]: La implantación del grado en finanzas y contabilidad en el contexto del espacio europeo de educación superior: el caso de la universidad de Sevilla. Revista Española de Financiación y Contabilidad, vol. 38, núm. 142: 293-310.

FLÓREZ, R. y E. ALBELDA [2012]: Una experiencia de trabajo en equipo con soporte documental para la formación de competencias en Contabilidad Financiera. Revista de Educación en Contabilidad, Finanzas y Administración de Empresas, núm. 3: 67-94.

FUERTES, I., GILL DE ALBORNOZ, B. y J.J. VICIANO [2015]: ¿ Contribuyen los cuestionarios online a mejorar el rendimiento en una evaluación sumativa? Una experiencia en el área de Contabilidad. Revista de Educación en Contabilidad, Finanzas y Administración de Empresas, núm. 6: 35-57.

GANDÍA, J.L y M.D. MONTAGUD [2011]: Innovación docente y resultados del aprendizaje: un estudio empírico en la enseñanza de la contabilidad de costes. Revista Española de Financiación y Contabilidad, vol. 40, núm. 152: 677-698.

GARANDILLAS, M., SOMOHANO, F.M. y F.J. MARTÍNEZ [2011]: Innovación y evaluación en el marco del Espacio Europeo de Educación Superior: Una experiencia piloto utilizando herramientas Web 2.0 Revista de Educación en Contabilidad, Finanzas y Administración de Empresas, núm. 2: 85-111.

GÓMEZ-RUIZ, L. y D. NARANJO-GIL [2011 [: La competencia de trabajo en grupo: una propuesta de actividad y de evaluación. Revista de Docencia Universitaria, vol. 9, núm. 2: 193-211.

HUANG, J. y S. MINTZ [1992]: International Accounting Education: A Global Perspective. The Accounting Educators' Journal, vol. 4, núm. 1: 69-85.

INTERNATIONAL FEDERATION OF ACCOUNTANTS. International Accounting Education Standards Board. [2008]: International Education Standards 1 - 8. N.Y., IFAC

JACKLING, B. [2013]: Global Adoption of International Financial Reporting Standards: Implications for Accounting Education. Issues in Accounting Education, vol. 28, núm. 2: 209-220.

JACKLING, B. LANGE, P. y R. NATOLI [2013]: Transitioning to IFRS in Australian Classrooms: impact on Teaching Approaches. Issues in Accounting Education, vol. 28, núm. 2: 263-275.

LARSON, R.K. Y D.L. STREET [2011]: IFRS Teaching Resources: Available and Rapidly Growing. Accounting Education: an International Journal, vol. 20, núm. 4: 317338.

MARÍN-GARCÍA, J.A., MILLARES-INSA, C., GARCÍA-SABATER, J.J. y P.I. VIDAL-CARRERAS [2008]: Enseñando Administración de Empresas con docencia basada en el trabajo en equipo de los estudiantes: Ventajas, inconvenientes y propuestas de actuación. Intangible Capital, vol. 42, núm. 2: 143-164.

MARTí, C. P. y N. ORGAZ [2011]: El cuestionario como herramienta de autoevaluación en el proceso de aprendizaje de la asignatura Contabilidad Financiera y Analítica. Revista de Educación en Contabilidad, Finanzas y Administración de Empresas, núm. 2: 51-66.

MARTí, C. P. y N. ORGAZ [2014]: Análisis del uso de cuestionarios en contabilidad financiera. Educación XX1, vol. 17, núm. 1: 271-290.

MINGORANCE, A.C. [2008]: Análisis comparado entre los resultados de una evaluación continua y otra puntual. El caso de la asignatura de macroeconomía. Revista de Investigación Educativa, vol. 26, núm. 1:95-120. 
MUNTER, P. y P. RECKERS [2009]: IFRS and Collegiate Accounting Curricula in the United States: 2008 A Survey of the Current State of Education Conducted by KPMG and the Education Committee of the American Accounting Association. Issues in Accounting Education, vol. 24, núm. 2: 131-139.

NEEDLES, B. [2010]: Accounting Education: The Impact of Globalization. Accounting Education: an International Journal, vol. 19, núm. 6: 601-605.

NELSON, L. Y B. SALOTTI [2013]: Adoption of IFRS in Brazil and the Consequences to Accounting Education. Issues in Accounting Education, vol. 28, núm. 2: 235-242.

OLIVERAS, E., CRESPO, P. y J.M. RAYA [2013]: El proceso de Bolonia en el área de contabilidad: Efectos sobre la satisfacción de los estudiantes. Revista de Educación en Contabilidad, Finanzas y Administración de Empresas, núm. 4: 2233.

PASCUAL, D., CAMACHO, M.M., URQUÍA, E. y A. MÜLLER [2011]: ¿̇Son los nuevos criterios de valoración en el marco del EEES adecuados para valorar el rendimiento académico de los alumnos? Experiencia en Contabilidad Financiera. Revista de Educación en Contabilidad, Finanzas y Administración de Empresas, núm. 2: 6783.

PERIÁÑEZ, I., LUENGO, M.J., PANDO, J., DE LA PEÑA, J.I. y F.J. VILLALBA [2010]: Competencias demandadas en los nuevos economistas. Revista de Educación en Contabilidad, Finanzas y Administración de Empresas, núm. 1: 59-77.

REZAEE, Z., SZENDI, J. y R. ELMORE [1997]: International Accounting Education: Insights from Academicians and Practitioners. International Journal of Accounting, vol. 32, núm. 1: 99-117.

RODRÍGUEZ MOLINUEVO, J.M. [2010]: Nuevos retos en la formación de los futuros profesionales contables. VII Jornadas de Docencia en Contabilidad. ASEPUC, Bilbao

STOLOWY, H. Y M. TENENHAUS [1998]: International accounting education in Western Europe. European Accounting Review, vol. 7, núm. 2: 289-314.

STONER, G.N. y A. SANGSTER [2013]: Teaching IFRS in the U.K.: Contrasting Experiences from Both Sides of the University Divide. Issues in Accounting Education, vol. 28, núm. 2: 291-307.

STOUT, D.E. y J.A. SCHWEIKART [1989]: The Relevance of the International Accounting Curriculum: A Comparison of Practitioner and Educator Opinions. Issues in Accounting Education, vol. 4, núm. 1: 126-143.

THOMAS, J. [2009]: Convergence: Businesses and Business Schools Prepare for IFRS. Issues in Accounting Education, vol. 24, núm. 3: 369-376.

VYSOTSKAYA, A. y M. PROKOFIEVA [2013]: The Difficulties of Teaching IFRS in Russia. Issues in Accounting Education, vol. 28, núm. 2: 309-319.

WELLS, M. [201 1]: Framework-based Approach to Teaching Principle-based Accounting Standards. Accounting Education: an International Journal, vol. 20, núm. 4: 303316.

WELLS, P., FIEGER, P. y P. DE LANGE [2008]: Integrating a virtual learning environment into a second year accounting course: Determinants of overall student perception. Accounting \& Finance, vol. 48, núm. 3: 503-518.

ZHU, H., RICH, K., MICHENZI, A. y J. CHERUBINI [2011]: User-Oriented IFRS Education in Introductory Accounting at U.S. Academic Institutions: Current Status and Influencing Factors. Issues in Accounting Education, vol. 26, núm. 4: 725-750. 